\title{
Improved Backstepping Control of a DFIG based Wind Energy Conversion System using Ant Lion Optimizer Algorithm
}

\author{
Zoubir Zeghdi $^{1 *}$, Linda Barazane ${ }^{1}$, Youcef Bekakra², Abdelkader Larabi ${ }^{1}$ \\ ${ }^{1}$ Department of Electrical Engineering, Faculty of Electronics and Computer Sciences, LSEI Laboratory, University of Sciences and \\ Technology of Houari Boumediene (USTHB), 16111 Algiers, P.O.B. 32, Algeria \\ ${ }^{2}$ Department of Electrical Engineering, Faculty of Technology, LEVRES Laboratory, University of El Oued, 39000 El Oued, P.O.B. 789 , \\ Algeria \\ * Corresponding author, e-mail: zzeghdi@usthb.dz
}

Received: 06 June 2021, Accepted: 06 July 2021, Published online: 13 December 2021

\begin{abstract}
In this paper, an improved Backstepping control based on a recent optimization method called Ant Lion Optimizer (ALO) algorithm for a Doubly Fed Induction Generator (DFIG) driven by a wind turbine is designed and presented. ALO algorithm is applied for obtaining optimum Backstepping control (BCS) parameters that are able to make the drive more robust with a faster dynamic response, higher accuracy and steady performance. The fitness function of the ALO algorithm to be minimized is designed using some indexes criterion like Integral Time Absolute Error (ITAE) and Integral Time Square Error (ITSE). Simulation tests are carried out in MATLAB/Simulink environment to validate the effectiveness of the proposed BCS-ALO and compared to the conventional BCS control. The results prove that the objectives of this paper were accomplished in terms of robustness, better dynamic efficiency, reduced harmonic distortion, minimization of stator powers ripples and performing well in solving the problem of uncertainty of the model parameter.
\end{abstract}

\section{Keywords}

Doubly Fed Induction Generator, wind turbine, Backstepping control, Ant Lion Optimizer Algorithm

\section{Introduction}

Wind energy is considered nowadays as a rapidly growing segment among other sources of renewable energy [1]. This is because this sort of energy is considered clean, geographically accessible, has a low cost, and especially useful in rural areas [2]. Moreover, it is intermittent and requires a high initial investment, increased transmission costs, and a wide land area. It was first employed in mechanical application areas before being utilized to produce electricity [3]. The total installed global wind power capacity at the end of the year of 2019 was $60.4 \mathrm{GW}$, which represents a $19 \%$ increase from installations in the year of 2018 and the second-best year historically for wind power [2]. The year of 2020 was expected to be a record year for wind power, with $76 \mathrm{GW}$ of new capacity estimated by GWEC. Moreover, the full effect of COVID-19 on wind power projects is still unknown [2].

On the other side, the DFIG becomes one of the most commonly utilized variable speed wind turbines due to its numerous benefits in improved reliability, supply division, high-power efficiency, control system ability, low maintenance costs, and full-power control capability [1].
In addition, induction generators may be regulated by utilizing different strategies like field-oriented control, indirect torque one ..., etc., using processes intended to control the DFIG's active and reactive power [3, 4]. Otherwise, Field Oriented Control (FOC) or Vector Control (VC) strategy is then combined and applied to the DFIG to make its dynamic behavior similar to the DC machine one which leads to the successful decoupling of the active and reactive power in such a system [5]. Nevertheless, it is important to know that the machine parameters must be precisely determined in the conception of the suggested controller [6].

However, in many real-life applications, the classic controller-based on vector control scheme is used to control the induction machine due to; its simple design, its easy implementation and well decoupling active and reactive powers $[4,6]$. However, it has some disadvantage. One of the major drawbacks of this control strategy is that the efficiency of the vector control process is mainly according to the parameters adjustment of the classical PI/PID controllers [7-9]. Nevertheless, the adjustment of the PI/PID 
controllers gains is usually achieved arbitrarily and manually using techniques that are very complex, tedious and time-consuming in a dynamic system with parametric uncertainties [10].

In the last years, some novel approaches such as artificial intelligence strategies have been employed in many research studies to overcome these drawbacks [11-15]. Furthermore, to improve the performances of the PI controller, many effective methods of tuning parameters have been suggested, such as fuzzy logic associated with the PI controller that does not introduce the chattering phenomenon as the sliding mode controller [13]. In [14], the authors introduce a combination of adaptive fuzzy design and PI-sliding mode controller. The authors suggest in [15] a Takagi-Sugeno Fuzzy method mode regulators applied to an induction motor. In [16], the authors use the MRAS speed estimator based on Type- 2 Fuzzy logic control for sensorless speed direct torque and flux control of an induction motor drive. In addition, the literature has proposed fuzzy-neural strategies as a robust control for electrical drives designed to optimize the performance of the overall processes under consideration $[17,18]$. Neuro-fuzzy systems directly equate to the advantages of ANNs and AFL schemes. The key aim of using the ANFIS technique is to provide the fuzzy structure automatically through the use of neural network schemes [19, 20].

Otherwise, several approaches have been suggested in the kinds of literature to clarify the efficiency of backstepping control [21-27]. The authors in [22] use an effective nonlinear backstepping control strategy of a WECS based on a DFIG in order to ensure the system's overall stability. Therefore, to enhance the efficiency of the WECS based on a permanent magnet synchronous generator attached to the network, the authors successfully implemented nonlinear backstepping control on a real system in [23]. Moreover, in order to optimize the performance of grid-connected DFIG, the authors in [24], suggest the combination of an integral backstepping control with the high-gain observer. In [25], the authors proposed an algorithm that mixes the nonlinear backstepping strategy with the FOC for controlling the active and reactive power of the DFIG, as well as regulating the energy transferred to the power network. The authors in [26], presented, a combination of the PI controller and backstepping control strategy for the separately regulation of the transferred active and reactive powers from the stator of the DFIG to the power networks. A backstepping control for stand-alone DFIG has been designed in [27] to regulate the stator voltage and satisfy the requirement power fluctuations and wind speed impacts.
The aim of this paper is to improve the control of the active and reactive power utilizing backstepping control taking into consideration the DFIG parameter variations. In general, the choice of parameters for backstepping control is random. The optimal choice of parameters values of the Lyapunov function should yield a better result.

Several studies have recently discussed the utilization of nature-inspired and bio-inspired optimization approaches to improve power system control behavior [28-30]. In this regard, metaheuristic algorithms are inspired by nature which mimics biological and physical phenomena or the behavior of animals. In this area, some of the major wellknown algorithms are: Genetic Algorithms (GA) [31], Particle Swarm Optimization (PSO) [32], and Ant Colony Optimization (ACO) [33]. Some of the recent proposed and cited algorithms are: The Firefly Algorithm (FA) [34], Grey Wolf Optimizer (GWO) [35], and Colliding Bodies Optimization (CBO) [36]. An improved predictive direct power control of shunt active power filter based on GWO and ALO algorithms for simulation and experimental studies is suggested in [37] to reduce the maximum overshoot and undershoot of the DC-link voltage response, and minimize power ripples with low current distortion. In [38], doubly fed induction motor is controlled using direct torque control technique. The speed is controlled by using an integral-proportional controller tuned by a recent optimization method called rooted tree optimization algorithm to improve the performance of motor response such as to minimize the settling time, and reduce the undershoot and overshoot.

In this paper, optimal parameters of the backstepping control are determined by using a recently nature-inspired algorithm named Ant Lion Optimizer (ALO) [39-41]. The use of ALO algorithm that can determine the optimal gain values according to uncertainty parameters of BCS by minimizing a chosen criterion for accomplishing the better efficiency of this control and that is able to make the drive more robust, with the faster dynamic response, reduced harmonic distortion, minimization of stator powers ripples, higher accuracy and steady performance, while assuring the respect of the dynamic limits of the DFIG.

The major contribution of the present paper is summarized as follows:

- ALO is a recent nature-inspired algorithm, used to obtain better solutions and improve the performance of the conventional backstepping control based on the DFIG. 
- ALO algorithm succeeds in finding a better trade-off between conflicting objectives (reduced overshoot, reduced response time, minimized power ripples and lower THD) than the conventional backstepping approach.

- The proposed strategy is validated by a simulation study.

In this way, the present paper is structured as follows: Section II presents the model of wind turbine with MPPT technique and the DFIG. The power control strategy related to the DFIG is explained in Section III. Section IV deals with BCS-ALO's control design. ALO algorithm is employed to adjust the BCS parameters (optimal values) and in section $\mathrm{V}$, simulation results, will be performed by Matlab/Simulink software. These latter will be presented, commented and discussed to demonstrate their ability to control the active and reactive power. Finally, Section VI is dedicated to the conclusions.

\section{Modelling of system understudy}

This section summarizes the model of the studied system, as described in Fig. 1, which consists of an overall grid linked-wind turbine composed of a DFIG that is directly attached to the power grid through its stator and indirectly through its rotor with the intermediaries of Rotor Side Converter (RSC) and Grid Side Converter (GSC) $[1,5]$.

\subsection{Wind Turbine model and MPPT}

The aerodynamic power $P_{t}$ transformed by a wind turbine is closely dependent on the power coefficient $C_{p}$. It is provided by the next expression as $[1,7]$ :

$P_{t}=\frac{1}{2} C_{p}(\lambda, \beta) \rho \pi R^{2} V^{3}$.

The blade velocity is provided by:

$T_{\text {aer }}=\frac{P_{t}}{\Omega_{t}}$.

A wind turbine can guarantee that a certain percentage of the captured wind power is converted into electricity. This percentage is expressed by $C_{p}(\lambda, \beta)$, which is considered to become a function of wind velocity, turbine speed and a pitch angle of particular blades of a wind turbine, respectively.

The tip speed ratio is defined as follows:

$$
\begin{aligned}
& \lambda=\frac{\Omega_{t} R}{V}, \\
& \Omega_{t}=\frac{\Omega_{\text {mec }}}{G} .
\end{aligned}
$$

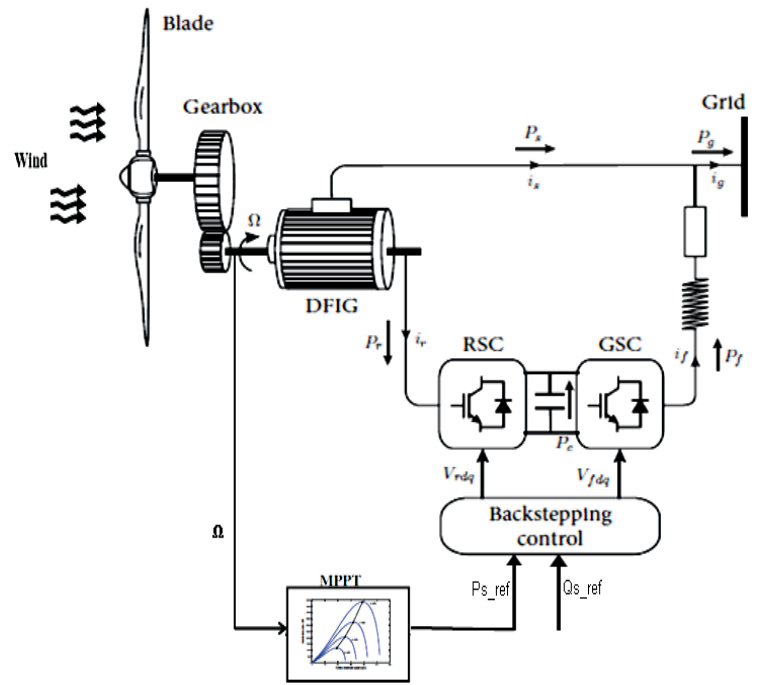

Fig. 1 Block scheme of the studied system

The power coefficient utilized in this work for a wind turbine is represented mathematically as follows:

$C_{p}(\lambda, \beta)=0.5176\left(\frac{116}{\lambda_{i}}-0.4 \beta-5\right) \exp \left(\frac{-21}{\lambda_{i}}\right)+0.0068 \lambda$,

$\frac{1}{\lambda_{i}}=\frac{1}{\lambda+0.08 \beta}-\frac{0.035}{\beta^{3}+1}$.

The maximum power change for DFIG rotation speed is pre-defined for each wind turbine. Thus, for MPPT, the control system must follow the wind turbine's tracking characteristic curve (TCC) [7]. The TCC of each wind turbine is similar to that one depicted in Fig. 2. Consequently, wind speed changes the turbine's speed while keeping the optimal tip speed ratio where the MPPT to going be regulated by the reference rotor speed [4]. As seen in Fig. 2, this technique is named MPPT. For each turbine, the reference speed and mechanical properties are identified in the following expression [7]:

$\Omega^{*}=\frac{\lambda\left(C_{p \max }\right) \cdot V}{R}$.

It could really find from Fig. 2, that at the point where $C_{p}$ is maximized, there is a particular angular frequency at which the power output of a wind turbine is optimum. In order to achieve the optimal power curve (MPPT curve), all the maximum power points of each power curve are linked.

Fig. 3 is demonstrating the relationship between the $C_{p}$ and $\lambda$ of the various values of $\beta$.

In this study, the optimal values of $C_{p}$ and $\lambda$ are obtained from Fig. 3 and are exactly equal, respectively, to: $C_{p \text {-max }}=0.48$ and $\lambda_{\text {opt }}=8.1$, for $\beta=0^{\circ}$. 


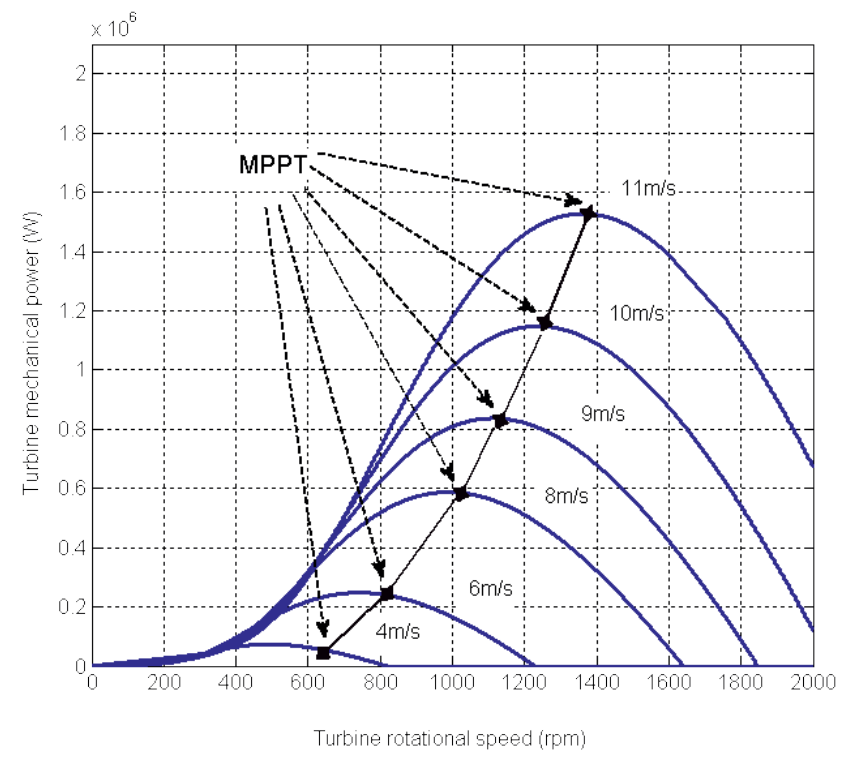

Fig. 2 Turbine powers versus various speed characteristics for different wind speeds, with the indication of the maximum power tracking curve

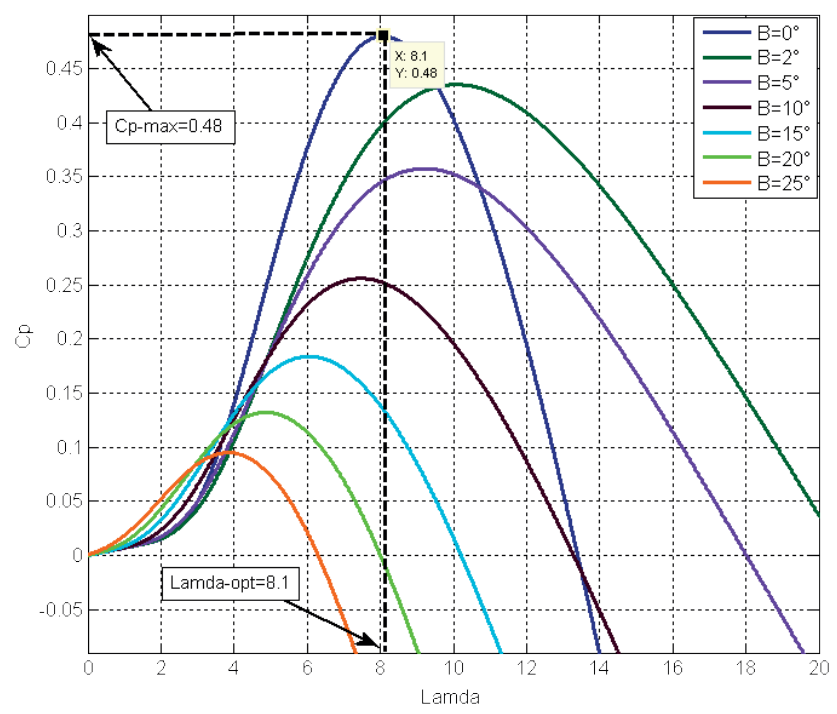

Fig. 3 The $C_{p}$ versus $\lambda$ characteristics, for various values of the pitch angle $\beta$

\subsection{DFIG model}

DFIG's electrical equations are expressed as follows [2-5]:

$$
\left\{\begin{array}{l}
V_{s q}=R_{s} I_{s q}+\frac{d \phi_{s q}}{d t}+\omega_{s} \phi_{s d} \\
V_{s d}=R_{s} I_{s d}+\frac{d \phi_{s d}}{d t}-\omega_{s} \phi_{s q} \\
V_{r q}=R_{r} I_{r q}+\frac{d \phi_{r q}}{d t}+\omega_{r} \phi_{r d} \\
V_{r d}=R_{r} I_{r d}+\frac{d \phi_{r d}}{d t}-\omega_{r} \phi_{r q}
\end{array}\right.
$$

with:

$$
\left\{\begin{array}{l}
\phi_{s q}=L_{s} I_{s q}+L_{m} I_{r q} \\
\phi_{s d}=L_{s} I_{s d}+L_{m} I_{r d} \\
\phi_{r q}=L_{r} I_{r q}+L_{m} I_{s q} \\
\phi_{r d}=L_{r} I_{r d}+L_{m} I_{s d}
\end{array} .\right.
$$

The electromagnetic torque is defined by:

$$
C_{e m}=\frac{3}{2} p \frac{L_{m}}{L_{s}}\left(\phi_{s q} I_{r d}-\phi_{s d} I_{r q}\right) \text {. }
$$

The active and reactive powers of the stator are expressed by:

$$
\left\{\begin{array}{l}
P_{s}=\frac{3}{2}\left(V_{s d} I_{s d}+V_{s q} I_{s q}\right) \\
Q_{s}=\frac{3}{2}\left(V_{s q} I_{s d}-V_{s d} I_{s q}\right)
\end{array} .\right.
$$

\section{Power control strategy}

The FOC control rules are extracted from the DFIG formulations using a Park transformation especially involving the rotating flux $(d-q)$ and the stator flux orientation, as well as the setting of the stator flux synchronized with $d$-axis $[5,7]$.

$\phi_{s q}=0$, and $\phi_{s d}=\phi_{s}$

In this case, the torque becomes:

$$
C_{e m}=-\frac{3}{2} p \frac{L_{m}}{L_{s}}\left(\phi_{s d} I_{r q}\right)
$$

In addition, the machines used in wind conversion are generally high power, so, the stator resistance $R_{s}$ can be neglected $[6,7]$, the DFIG's mathematical model could be simplified as follows:

$$
\begin{aligned}
& \left\{\begin{array}{l}
\phi_{s q}=0=L_{s} I_{s q}+L_{m} I_{r q} \\
\phi_{s d}=\phi_{s}=L_{s} I_{s d}+L_{m} I_{r d}
\end{array}\right. \\
& \left\{\begin{array}{l}
V_{s q}=V_{s}=\omega_{s} \phi_{s d} \\
V_{s d}=0
\end{array}\right.
\end{aligned}
$$

$\left\{\begin{array}{l}I_{s q}=-\frac{L_{m}}{L_{s}} I_{r q} \\ I_{s d}=\frac{\phi_{s d}}{L_{s}}-\frac{L_{m}}{L_{r}} I_{r d}\end{array}\right.$

$$
\left\{\begin{array}{l}
P_{s}=\frac{3}{2} V_{s} I_{s q} \\
Q_{s}=\frac{3}{2} V_{s} I_{s d}
\end{array}\right.
$$


The stator power is regulated independently by the rotor voltages $V_{r d}$ and $V_{r q}$. The stator power could be written into the $d-q$ reference frame by replacing Eq. (16) in Eq. (17) as follows:

$$
\left\{\begin{array}{l}
P_{s}=-\frac{3}{2} \frac{L_{m} V_{s}}{L_{s}} I_{r q} \\
Q_{s}=\frac{3}{2} \frac{V_{s}^{2}}{\omega_{s} L_{s}}-\frac{3}{2} \frac{L_{m} V_{s}}{L_{s}} I_{r d}
\end{array} .\right.
$$

The equations below describe the relationship between stator powers and rotor currents:

$$
\left\{\begin{array}{l}
I_{r q}=-\frac{2}{3} \frac{L_{s}}{L_{m} V_{s}} P_{s} \\
I_{r d}=\frac{2}{3} \frac{V_{s}^{2}}{\omega_{s} L_{s}}-\frac{2}{3} \frac{L_{s}}{L_{m} V_{s}} Q_{s}
\end{array} .\right.
$$

The stator active and reactive powers are controlled indirectly by $I_{r q}$ and $I_{r d}$, respectively, due to the constant stator voltage. The voltages of the rotor could be expressed according to the rotor currents, as follows:

$$
\left\{\begin{array}{l}
V_{r q}=R_{r} I_{r q}+g \omega_{s}\left(L_{r}-\frac{L_{m}{ }^{2}}{L_{s}}\right) I_{r d}+g \frac{L_{m} V_{S}}{L_{s}} \\
V_{r d}=R_{r} I_{r d}-g \omega_{s}\left(L_{r}-\frac{L_{m}{ }^{2}}{L_{s}}\right) I_{r q}
\end{array}\right.
$$

where:

$$
\sigma=1-\frac{L_{m}^{2}}{L_{r} L_{s}} \text { is the Leakage coefficient and } g=\frac{\omega_{s}-\omega_{r}}{\omega_{s}}
$$

is the slip.

The voltages of the rotor may be expressed according to the currents of the rotor as follows:

$\left\{\begin{array}{l}V_{r q}=-\frac{2}{3}\left(\frac{R_{r}+\sigma L_{r}}{\frac{V_{s} L_{m}}{L_{s}}} s\right) \cdot P_{s}-\frac{2}{3}\left(g \omega_{s} \frac{\sigma L_{r}}{\frac{V_{s} L_{m}}{L_{s}}}\right) \cdot Q_{s}+g V_{s}\left(\frac{\sigma L_{r}}{L_{m}}+\frac{L_{m}}{L_{s}}\right) \\ V_{r d}=\frac{2}{3}\left(g \omega_{s} \frac{\sigma L_{r}}{\frac{V_{s} L_{m}}{L_{s}}}\right) \cdot P_{s}-\frac{2}{3}\left(\frac{R_{r}+\sigma L_{r}}{\frac{V_{s} \omega_{s}}{L_{s}}} S\right) \cdot Q_{s}+\left(\frac{R_{r} V_{s}}{\omega_{s} L_{m}}+\frac{\sigma L_{r} V_{s}}{\omega_{s} L_{m}} S\right)\end{array}\right.$

A schematic diagram of the control system could be designed from the above equations, as shown in Fig. 4.

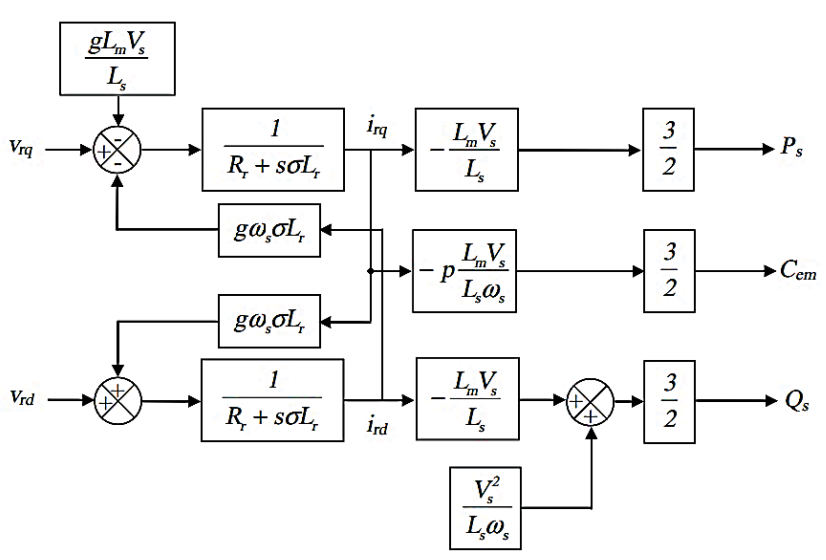

Fig. 4 Schematic diagram of the basic model of DFIG

\section{Control design}

The components of the studied system are: A three-bladed rotor with a mechanical gearbox, a DFIG, a DC-link capacitor, two power converters (RSC and GSC) and a grid. The control scheme includes active and reactive power control is given as presented in Fig. 1.

\subsection{Backstepping control of DFIG}

In recent years, several nonlinear control approaches have been suggested. One of the most major strategies in the literature [21-27] is the backstepping technique. The basic idea of the backstepping strategy is to stabilize the system from the first subsystem by stabilizing the defined function through a chosen Lyapunov function [23]. The backstepping approach is generally a modern control scheme of nonlinear systems. This enables the system to work using a control law that is determined successively and automatically choosing a Lyapunov function [25]. The goal is to obtain zero errors convergence, therefore stabilizing and balancing the system which enables the output to track a reference [25]. Therefore, two backstepping controls are utilized in this work to regulate the active and reactive power of the DFIG, as contrary to some researchers [23, 24, 26, 27], who utilize more than two controllers (three or four controllers).

In this section, a backstepping's control approach is applied to the DFIG. The control system is structured in such a manner that the general design of the FOC is conserved. On the other hand, it is also important to remark that the backstepping strategy is based here on the theory of the VC, and employed to control the DFIG. In this situation, the control will be applied in the reference frame $(d-q)$, with taking into consideration the stator flux orientation [23]: 


$$
\left\{\begin{array}{l}
\phi_{s q}=0 \\
\phi_{s d}=\phi_{s}
\end{array} .\right.
$$

The equations below are the derivative rotor currents:

$$
\left\{\begin{array}{l}
I_{r q}^{\bullet}=\frac{d I_{r q}}{d t}=\left(V_{r q}-R_{r} I_{r q}-g \omega_{s} L_{r} \sigma I_{r d}-g \frac{L_{m} V_{S}}{L_{s}}\right) \frac{1}{L_{r} \sigma} . \\
I_{r d}^{\bullet}=\frac{d I_{r d}}{d t}=\left(V_{r d}-R_{r} I_{r d}+g \omega_{s} L_{r} \sigma I_{r q}\right) \frac{1}{L_{r} \sigma}
\end{array}\right.
$$

The following equations expressed the relation between stator powers and rotor currents:

$$
\left\{\begin{array}{l}
I_{r q_{-} r e f}=-\frac{2}{3} \frac{L_{s}}{V_{s} L_{m}} P_{s_{-} r e f} \\
I_{r_{-} \text {ref }}=\frac{2}{3} \frac{V_{s}^{2}}{\omega_{s} L_{s}}-\frac{2}{3} \frac{L_{s}}{V_{s} L_{m}} Q_{s_{-} r e f}
\end{array} .\right.
$$

The derivatives of the rotor reference current equations are as follows:

$$
\left\{\begin{array}{l}
I^{\bullet}{ }_{r q_{-} r e f}=-\frac{2}{3} \frac{L_{s}}{L_{m} V_{s}} P_{s_{-} r e f}^{\bullet} \\
I^{\bullet}{ }_{\text {rd_ref }}=-\frac{2}{3} \frac{L_{s}}{L_{m} V_{s}} Q_{s_{-} r e f}^{\bullet}
\end{array}\right.
$$

The synthesis of this control can be achieved in two steps. The control voltage is determined using Lyapunov functions and established in two steps as regards:

Step 1: define the tracking error:

$e_{1}$ and $e_{2}$ represent the errors between the measured variables of the currents $\left(I_{r q}\right.$ and $\left.I_{r d}\right)$ and the reference ones $\left(I_{r q_{\_} \text {ref }}\right.$ and $\left.I_{\text {rd_ref }}\right)$ are calculated in this step as follows:

$\left\{\begin{array}{l}e_{1}=\left(I_{r q_{-} r e f}-I_{r q}\right) \\ e_{2}=\left(I_{r d_{-} r e f}-I_{r d}\right)\end{array}\right.$.

The error's derivative is calculated as follows:

$$
\left\{\begin{array}{l}
e_{{ }_{1}}^{\bullet}=\left(I^{\bullet}{ }_{r q_{2} r e f}-I^{\bullet}{ }_{r q}\right) \\
e_{2}^{\bullet}=\left(I^{\bullet}{ }_{r d_{2} r e f}-I^{\bullet}{ }_{r d}\right)
\end{array} .\right.
$$

The function of Lyapunov is written as follows:

$v=\frac{1}{2}\left(e_{1}^{2}+e_{2}^{2}\right)$.

In order to impose the Lyapunov function derivative to zero, the errors should be selected as follows:

$$
e_{1}^{\bullet}=-k_{1} e_{1} \text { and } e_{2}^{\bullet}=-k_{2} e_{2} \text {. }
$$

The Lyapunov function's time derivative is as follows:

$v^{\bullet}=-k_{1} e_{1}^{2}-k_{2} e_{2}^{2}<0$,

with: $k_{1}>0$ and $k_{2}>0$.

This indicates that our system is globally stable. By replacing the currents' derivatives $I_{r q_{\_} \text {ref }}$ and $I_{r d_{\text {_ref }}}$ by their values, the formulation of the derivative errors is obtained by:

$\left\{\begin{array}{l}e_{1}^{\bullet}=\left(\left(-\frac{2}{3} \frac{L_{s}}{L_{m} V_{s}} P_{s_{-} r e f}^{\cdot}\right)-\frac{1}{L_{r} \sigma}\left(V_{r q}-R_{r} I_{r q}-g \omega_{s} L_{r} \sigma I_{r d}-g \frac{L_{m} V_{S}}{L_{s}}\right)\right) \\ e_{2}^{\bullet}=\left(\left(-\frac{2}{3} \frac{L_{s}}{L_{m} V_{s}} Q_{s_{-} r e f}^{\cdot}\right)-\frac{1}{L_{r} \sigma}\left(V_{r d}-R_{r} I_{r d}+g \omega_{s} L_{r} \sigma I_{r q}\right)\right)\end{array}\right.$

$\left\{\begin{array}{l}e_{1}=\left(\left(-\frac{2}{3} \frac{L_{s}}{L_{m} V_{S}} P_{s_{-}}^{\cdot}{ }_{r e f}\right)-\frac{1}{L_{r} \sigma} V_{r q}-\frac{1}{L_{r} \sigma}\left(-R_{r} I_{r q}-g \omega_{s} L_{r} \sigma I_{r d}-g \frac{L_{m} V_{S}}{L_{s}}\right)\right) \\ \dot{e}_{2}=\left(\left(-\frac{2}{3} \frac{L_{s}}{L_{m} V_{s}} Q_{s_{-} r e f}\right)-\frac{1}{L_{r} \sigma} V_{r d}-\frac{1}{L_{r} \sigma}\left(-R_{r} I_{r d}+g \omega_{s} L_{r} \sigma I_{r q}\right)\right)\end{array}\right.$

Step 2: the derivation of the virtual control from its desired value can be defined as:

By replacing the derivatives of the error by their values:

$$
\left\{\begin{array}{l}
-k_{1} e_{1}=\left(\left(-\frac{2}{3} \frac{L_{s}}{L_{m} V_{s}} P_{S_{-} r e f}^{\bullet}\right)-\frac{1}{L_{r} \sigma} V_{r q}-\frac{1}{L_{r} \sigma}\left(-R_{r} I_{r q}-g \omega_{s} L_{r} \sigma I_{r d}-g \frac{L_{m} V_{S}}{L_{s}}\right)\right) \\
-k_{2} e_{2}=\left(\left(-\frac{2}{3} \frac{L_{s}}{L_{m} V_{s}} Q_{s_{-} r e f}^{\bullet}\right)-\frac{1}{L_{r} \sigma} V_{r d}-\frac{1}{L_{r} \sigma}\left(-R_{r} I_{r d}+g \omega_{s} L_{r} \sigma I_{r q}\right)\right)
\end{array}\right.
$$

Finally, the selection of the control law is as regards:

$\left\{\begin{array}{l}V_{r q}=\left(L_{r} \sigma\left(-\frac{2}{3} \frac{L_{s}}{L_{m} V_{s}} P_{s_{-} r e f}^{\bullet}+k_{1} e_{1}\right)+R_{r} I_{r q}+g \omega_{s} L_{r} \sigma I_{r d}+g \frac{L_{m} V_{S}}{L_{s}}\right) \\ V_{r d}=\left(L_{r} \sigma\left(-\frac{2}{3} \frac{L_{s}}{L_{m} V_{s}} Q_{s_{-} r e f}+k_{2} e_{2}\right)+R_{r} I_{r d}-g \omega_{s} L_{r} \sigma I_{r q}\right)\end{array}\right.$

This leads to the conclusion that the system is globally stable. The parameters $k_{1}$ and $k_{2}$ are positive constants, the excellent selection of these parameters ensure stability and the fast dynamic response.

The selection of $k_{1}$ and $k_{2}$ is arbitrary, for these, an optimization method named Ant Lion Optimizer (ALO) algorithm is proposed to obtain optimal values of these parameters in the next section.

Fig. 5 illustrates a block diagram of the proposed backstepping control scheme. 


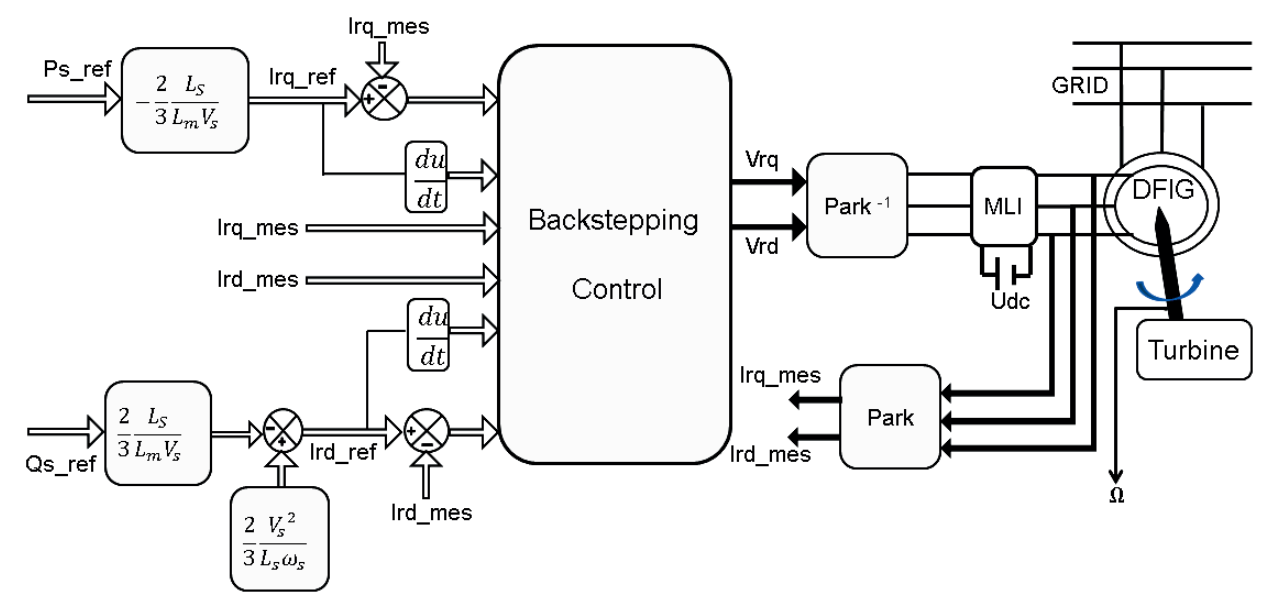

Fig. 5 Block diagram of the proposed backstepping control approach design for the DFIG driven by wind turbines

\subsection{Optimization of Backstepping control parameters}

\subsubsection{Overview of the Ant Lion Optimizer Algorithm}

Ant Lion Optimizer (ALO) is a recent nature-inspired algorithm presented in [39]. The ALO emulate the hunting mechanism of ant lions in nature.

An ant lion makes inverted cone-shaped pits in the sands with its massive jaws [40, 41], as described in Fig. 6(a) [39]. These pits are used for catching ants.

The larva hides under the cone's bottom and waits for the ants to fall in that pits after digging the trap [40, 41], as explained in Fig. 6(b) [39].

If the ants trap in those pits, then the ant lion tries to catch it. After hunting, ant lions will make the pits clean for another hunt [40].

\section{Random walk of ants}

As the movement of ants is randomly in nature when looking for food, a random walk is selected to model the motion of ants as regards [41]:

$$
X(t)=\left[\begin{array}{l}
0, \operatorname{cumsum}\left(2 r\left(t_{1}\right)-1\right), \text { cumsum }\left(2 r\left(t_{2}\right)-1\right), \ldots . . \\
\ldots \ldots \ldots, \text { cumsum }\left(2 r\left(t_{n}\right)-1\right)
\end{array}\right],
$$

where cums calculate the cumulative sum and $r(t)$ is identified as:

$$
r(t)=\left\{\begin{array}{ll}
1 & \text { if } \text { rand }>0.5 \\
0 & \text { if } \text { rand } \leq 0.5
\end{array}\right\} \text {. }
$$

To create a view of this random walk, Fig. 7 shows three random walks in 500 iterations [39].

From Fig. 7, it is possible to confirm that the random walk employed could vary significantly across the origin (red trajectory), then it could become a growing behavior (black trajectory) or a decreasing trend (blue trajectory) [39]. The ants stochastically change their locations based on Eq. (34).

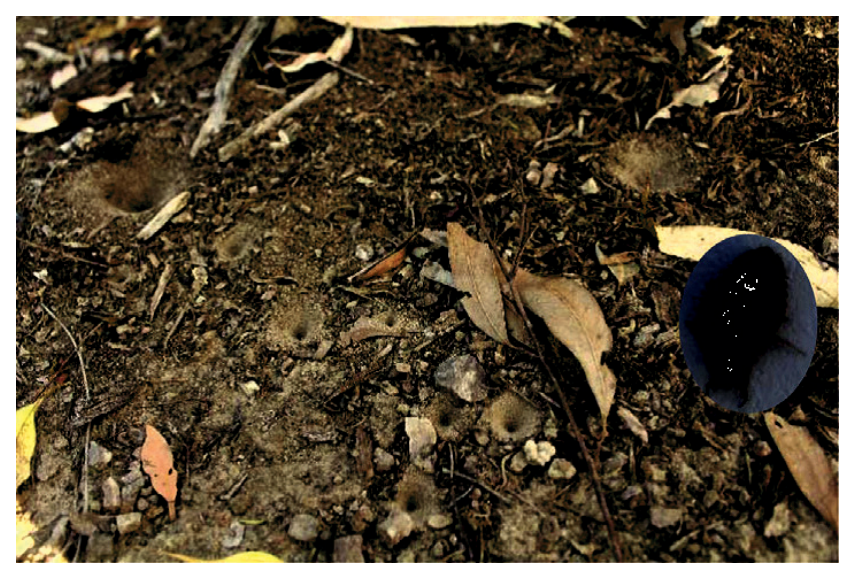

(a)
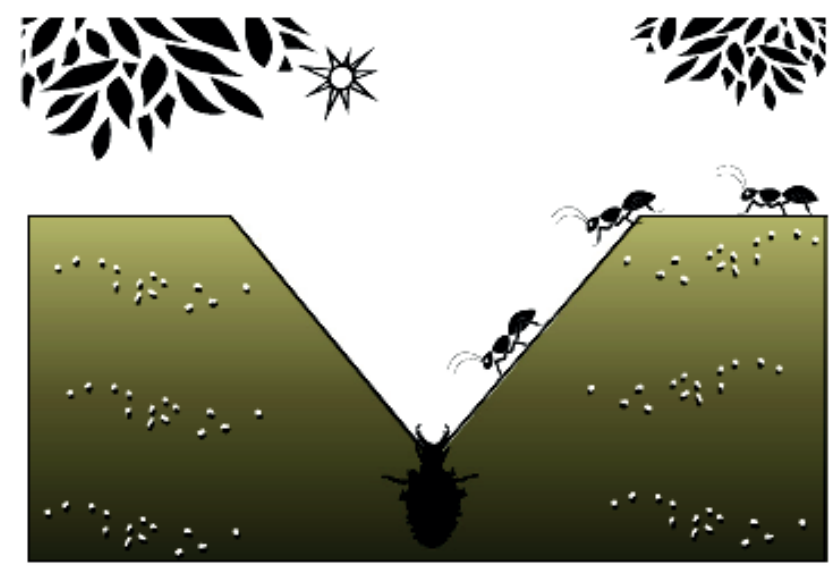

(b)

Fig. 6 Cone-shaped traps (a) and hunting behavior (b) of ant lions

In order to save the random walks in the search space, they are clarified by utilizing the next relationship:

$X_{i}^{t}=\frac{\left(X_{i}^{t}-A_{i}\right) \times\left(D_{i}-C_{i}^{t}\right)}{\left(D_{i}^{t}-A_{i}\right)}+C_{i}$. 


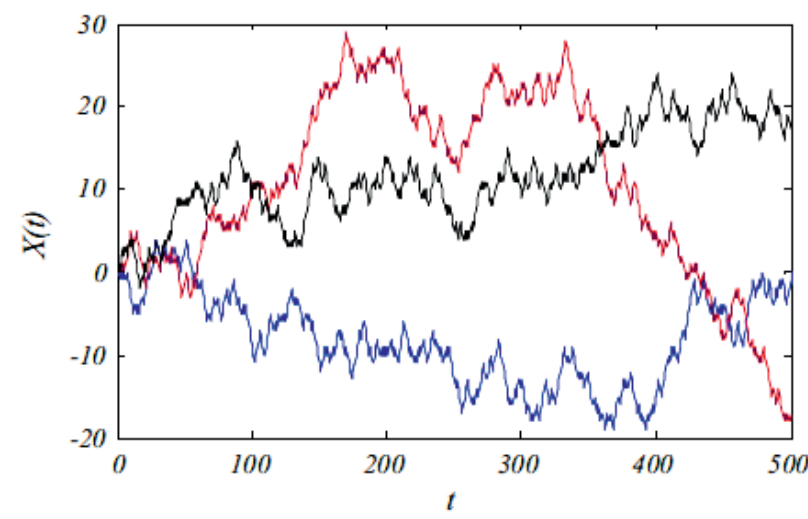

Fig. 7 Variations of the three random walks

The following matrix Eq. (37) shows the location of ants and the required fitness function matrix while the optimization process as follows:

$M_{\text {ant }}=\left[\begin{array}{cccc}\text { ant }_{1,1} & \text { ant }_{1,2} & \ldots . . & \text { ant }_{1, d} \\ \text { ant }_{2,1} & \text { ant }_{2,2} & \ldots . . & \text { ant }_{2, d} \\ : & : & : & : \\ \text { ant }_{n, 1} & \text { ant }_{n, 2} & \ldots . . & \text { ant }_{n, d}\end{array}\right]$.

Note that matrix $M_{a n t}$ is deemed to save the location of all ants.

During its optimization process, the objective function has been used, and the next matrix keeps the fitness values of all ants:

$M_{o a}=\left[\begin{array}{c}F_{t}\left(\left[\text { ant }_{1,1}, \text { ant }_{1,2}, \ldots . . \text { ant }_{1, d}\right]\right) \\ F_{t}\left(\left[\text { ant }_{2,1}, a n t_{2,2}, \ldots . . \text { ant }_{2, d}\right]\right) \\ : \\ F_{t}\left(\left[\text { ant }_{n, 1}, \text { ant }_{n, 2}, \ldots . . \text { ant }_{n, d}\right]\right)\end{array}\right]$.

Furthermore, if ants and ant lions disappear in the search area, the matrices of the suitable locations and fitness values are provided, respectively, as follows:

$$
\begin{aligned}
& M_{\text {antlion }}=\left[\begin{array}{cccc}
\text { antlion }_{1,1} & \text { antlion }_{1,2} & \ldots . . & \text { antlion }_{1, d} \\
\text { antlion }_{2,1} & \text { antlion }_{2,2} & \ldots . . & \text { antlion }_{2, d} \\
: & : & : & : \\
\text { antlion }_{n, 1} & \text { antlion }_{n, 2} & \ldots . . & \text { antlion }_{n, d}
\end{array}\right] \text {, }
\end{aligned}
$$

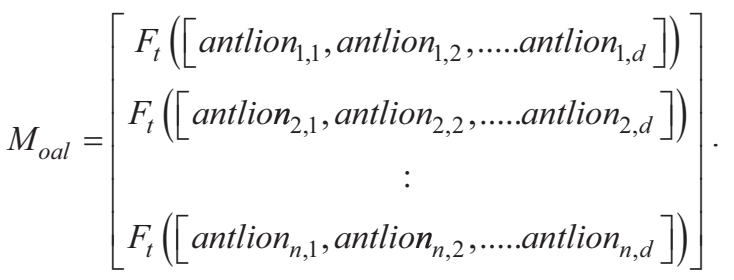

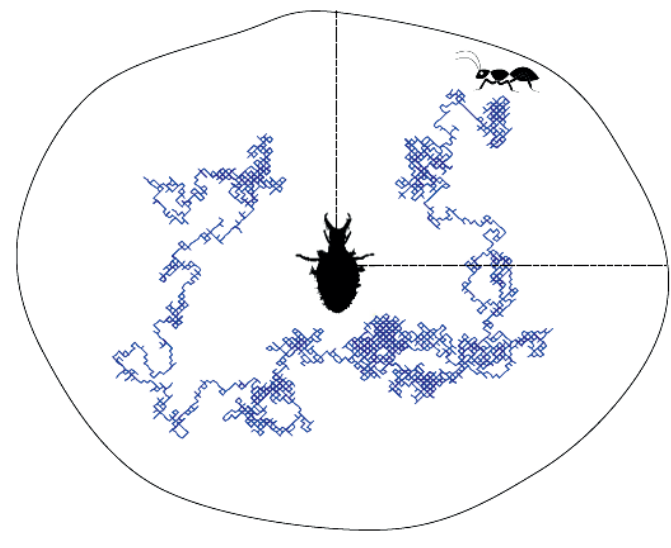

Fig. 8 Random walk of an ant inside an ant lion's trap

\section{Building trap}

Fig. 8 demonstrates how a roulette wheel is utilized to model the ant lion's trapping ability. This process gives the fittest ant lions a greater chance of capturing ants [39]. Trapping in ant lion pits

The trapping mathematical equations are described as follows:

$$
\begin{aligned}
& C_{i}^{t}=\text { Antlion }_{j}^{t}+C^{t}, \\
& D_{i}^{t}=\text { Antlion }_{j}^{t}+D^{t} .
\end{aligned}
$$

\section{Sliding ants towards ant lions}

Ant lions fire sand outwards in order to slide ants towards ant lions. The next equations can be used to model this behavior as follows:

$$
\begin{aligned}
& c^{t}=\frac{c^{t}}{I}, \\
& d^{t}=\frac{d^{t}}{I} .
\end{aligned}
$$

Catching prey and rebuilding the pit

At this stage, it will establish the objective function. Therefore, if the ant has the best objective function than the chosen ant lion one, it is important to update its location to the newest location of the hunted ants to enhance its possibility of capturing a novel one by using the next expression:

$$
\text { Antlion }_{j}^{t}=\text { Antlion }_{i}^{t} \text {; if } f\left(\text { Ant }_{i}^{t}\right)>f\left(\text { Antlion }_{j}^{t}\right) \text {. }
$$

Elitism

Elitism is appropriate for achieving the optimal solution at each stage during the optimization process. This can be modeled as follows:

$A n t_{i}^{t}=\frac{r_{a}^{t}+r_{e}^{t}}{2}$ 


\subsubsection{Optimal Backstepping control using ALO}

A law control described in Eq. (33) is designed to stabilize the overall system in section IV.

A problem appears when the design of the adaptive backstepping control is represented by choosing the values of design parameters for the backstepping control scheme.

In this section, the ALO algorithm is utilized to obtain optimum parameters $k_{1}$ and $k_{2}$ of conventional backstepping control.

In order to ensure the stability criteria of the system, the parameters $k_{1}$ and $k_{2}$ should be positive.

In the conventional backstepping control, these parameters are generally chosen arbitrarily (trial and error method). It's also possible that the parameters were selected correctly, but this does not guarantee that they were chosen optimally.

In this context, to overcome such a limitation, this paper proposed an approach that uses the ALO algorithm to choose the optimal values of the backstepping's control parameters.

It is noted that the ALO algorithm is utilized off-line to choose the optimum parameters' values for the backstepping control, and the control's performance fluctuates depending on the tuning parameters $\left(k_{1}\right.$ and $\left.k_{2}\right)$ based on the error of quadrature rotor current component $I_{r q}$ that is related to the active power $P_{s}$ and the error of direct rotor current component $I_{r d}$ related to the reactive power $Q_{s}$ of the DFIG as presented in Fig. 9.
The performance of any optimization strategy is according to the chosen objective function.

The aim of the random algorithm is to reduce the objective function in order to increase the system's behavior such as response time, overshoots and steady-state errors. All populations of ants, ant lions randomly, are decoded for $k_{1}$ and $k_{2}$ parameters.

In this study, Integral Time Absolute Error (ITAE) and Integral Time Square Error (ITSE) are used to evaluate the performance of the controller. ITAE and ITSE indexes are described as follows $[7,8]$ :

$$
\begin{aligned}
& \text { ITAE }=\int_{0}^{\infty} t \cdot|e(t)| \cdot d t, \\
& \text { ITSE }=\int_{0}^{\infty} t \cdot e(t)^{2} \cdot d t .
\end{aligned}
$$

ITAE aids in decreasing the maximum overshoot. Further, ITSE reduces the settling time, which cannot be accomplished with IAE or ISE based-adjusting.

The backstepping control approach based on the ALO algorithm has the following pseudo-code (Algorithm 1).

\section{Simulation results and discussion}

In this section, MATLAB/Simulink environment has been used to simulate the control process dynamics for a DFIG driven by a wind turbine in order to investigate the asymptotic stability of the proposed control and demonstrate its efficiency.

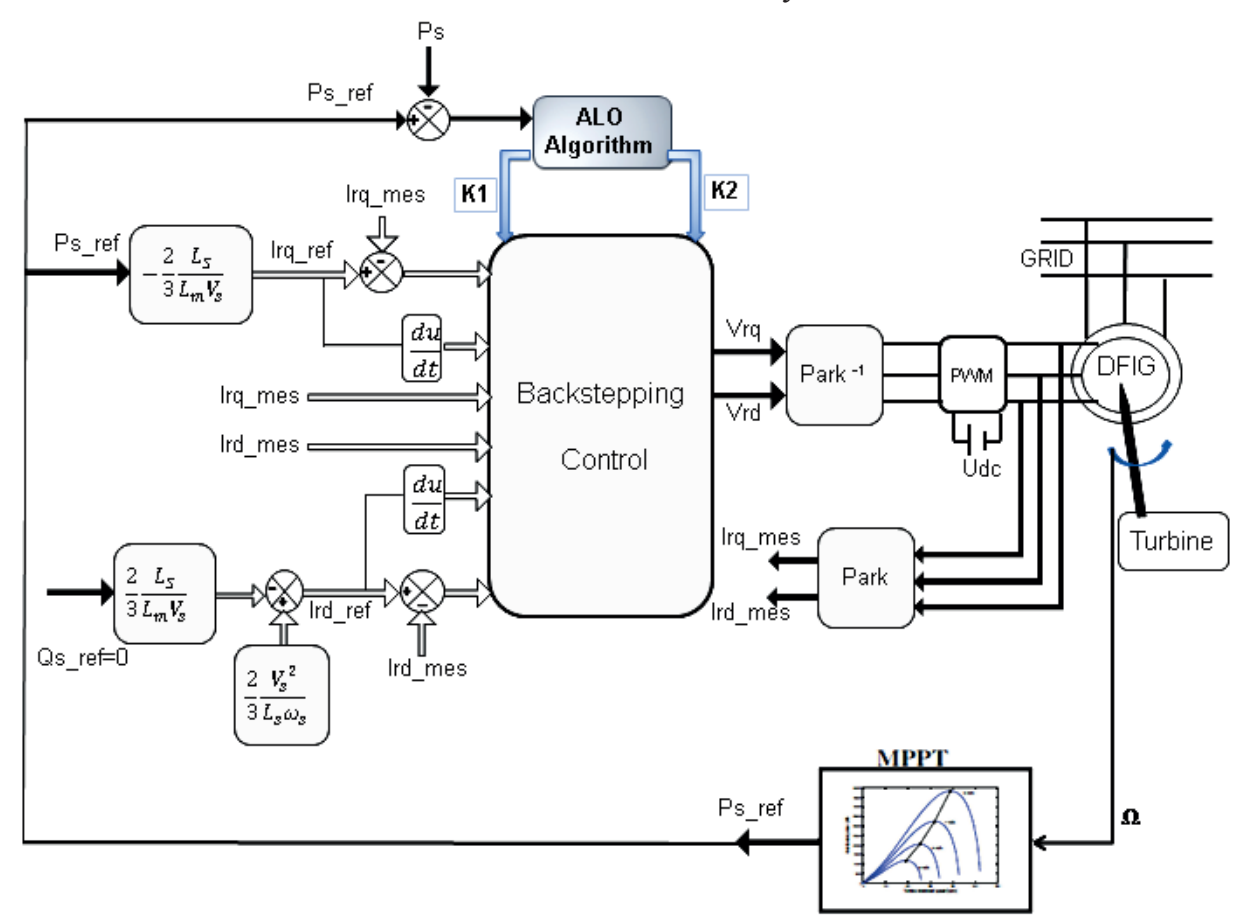

Fig. 9 Block diagram of the proposed Backstepping-ALO control approach design for DFIG driven by wind turbines 


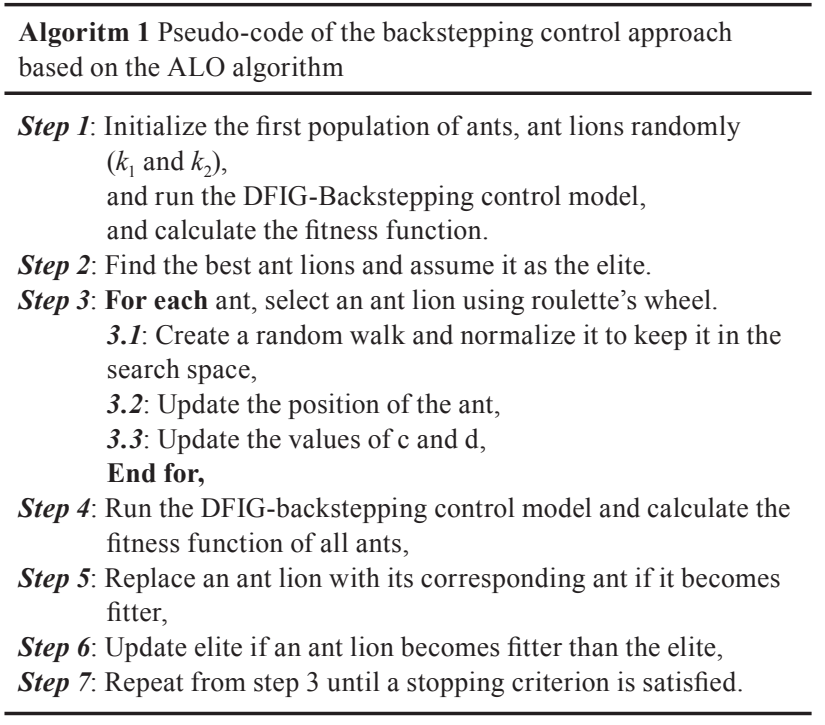

The parameters of wind turbine and the used DFIG are given in the Appendix (Tables 4 and 5), respectively, reported in the Appendix. The ALO parameters used in this work to tune the backstepping control parameters are the number of ant lions is 50; the maximum number of iterations is 100 .

Firstly, the ALO algorithm is mimicked off-line to find the optimal backstepping control parameters $\left(k_{1}\right.$ and $\left.k_{2}\right)$.

The first generation can be created stochastically where: $\operatorname{dim}=2\left(k_{1}\right.$ and $\left.k_{2}\right)$ from the initial parameters of the ALO.

The optimal parameters for the current iteration and fitness value of each optimal ant lion during the simulation are presented in Table 1, for determining the objective function.

The obtained cures of variations of fitness function and optimal parameters gain $k_{1}$ and $k_{2}$ by using the ALO algorithm, during the simulation are presented as shown in Figs. 10 and 11, respectively.

From Figs. 10 and 11, it is clear that the best fitness value could be obtained which is evaluated to $1.238 \mathrm{e}+006$ and seemed in iteration number 78 , and the optimal gains are $k_{1}=3.8790 \mathrm{e}+003$ and $k_{2}=4.2504 \mathrm{e}+003$.

As it is shown for these two optimized parameters, over around 100 iterations, the ALO strategy can prompt convergence and get a good fitness value. These results prove that the ALO strategy is capable to quickly and efficiently search for optimal backstepping control parameters.

Therefore, in order to verify the efficiency of the suggested optimal backstepping control approach based on ALO for the DFIG inserted in the wind energy conversion system, which is illustrated in Fig. 9, a comparison with the conventional backstepping (BCS) control is accomplished. The simulation results are presented for various scenarios.
Table 1 Fitness value of each optimal ant lion

\begin{tabular}{ccc}
\hline Iteration $\mathrm{N}^{\mathrm{o}}$ & Optimal Parameters & Fitness Value \\
\hline 1 & $K_{1}(1,1)=3.0765 \mathrm{e}+003$ & $1.273 \mathrm{e}+006$ \\
& $K_{2}(1,2)=7.7187 \mathrm{e}+003$ & \\
& $K_{1}(10,1)=6.4029 \mathrm{e}+003$ & $1.269 \mathrm{e}+006$ \\
10 & $K_{2}(10,2)=7.2510 \mathrm{e}+003$ & \\
& $K_{1}(20,1)=4.0833 \mathrm{e}+003$ & $1.253 \mathrm{e}+006$ \\
20 & $K_{2}(20,2)=4.4059 \mathrm{e}+003$ & \\
& $K_{1}(21,1)=3.7174 \mathrm{e}+003$ & $1.240 \mathrm{e}+006$ \\
21 & $K_{2}(21,2)=3.9166 \mathrm{e}+003$ & \\
& $K_{1}(50,1)=3.7953 \mathrm{e}+003$ & $1.240 \mathrm{e}+006$ \\
50 & $K_{2}(50,2)=4.1276 \mathrm{e}+003$ & \\
& $K_{1}(78,1)=3.8794 \mathrm{e}+003$ & $1.238 \mathrm{e}+006$ \\
78 & $K_{2}(78,2)=4.2508 \mathrm{e}+003$ & \\
& $K_{1}(100,1)=3.8790 \mathrm{e}+003$ & $1.238 \mathrm{e}+006$ \\
& $K_{2}(100,2)=4.2504 \mathrm{e}+003$ & \\
\hline
\end{tabular}

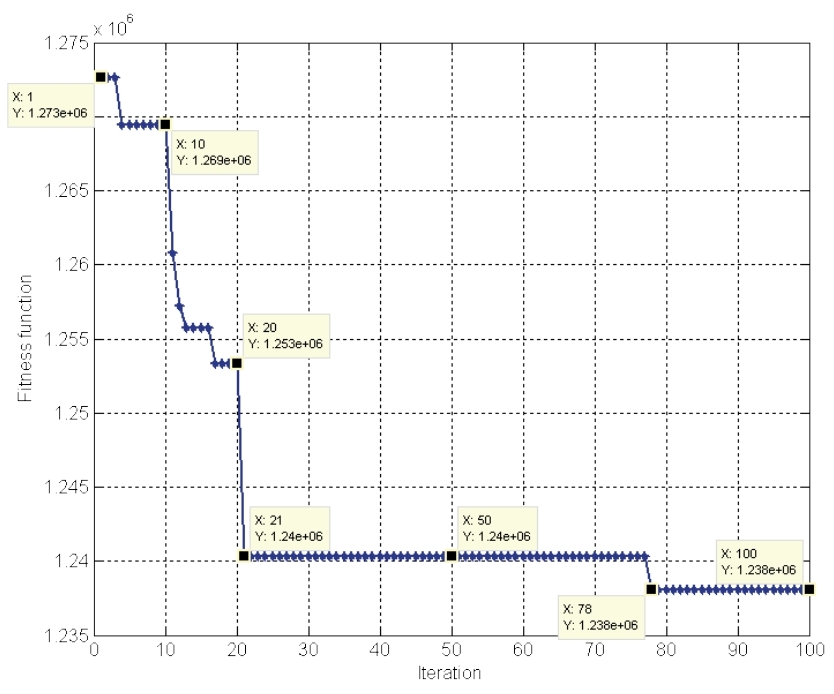

Fig. 10 Fitness function variation during simulation

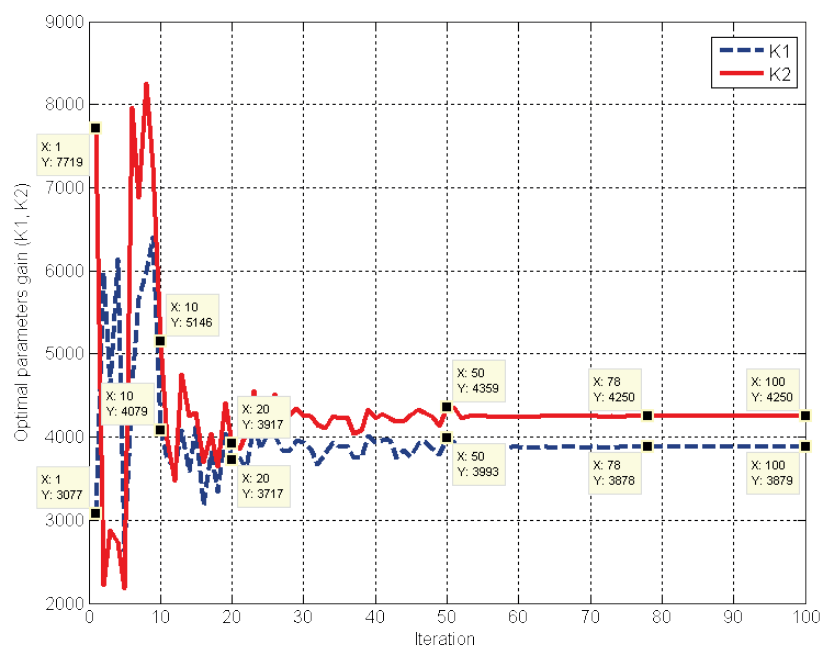

Fig. 11 Variations of the optimal parameters and during simulation 
Simulation results of both controls, BCS and BCS-ALO related to the tracking scenario of active and reactive power with their references, are depicted in Figs. 12(a) and (b), respectively, at variable wind speed with MPPT method and for unity power factor will be provided in the first test.

The aim of the second test is to evaluate the behavior of the two presented controls, conventional and optimal backstepping's method, for the tracking of a reference while considering that the mechanical speed is equal to its nominal value. The simulation results of active and reactive power, with their references, are presented as shown in Figs. 13 and 14, respectively.

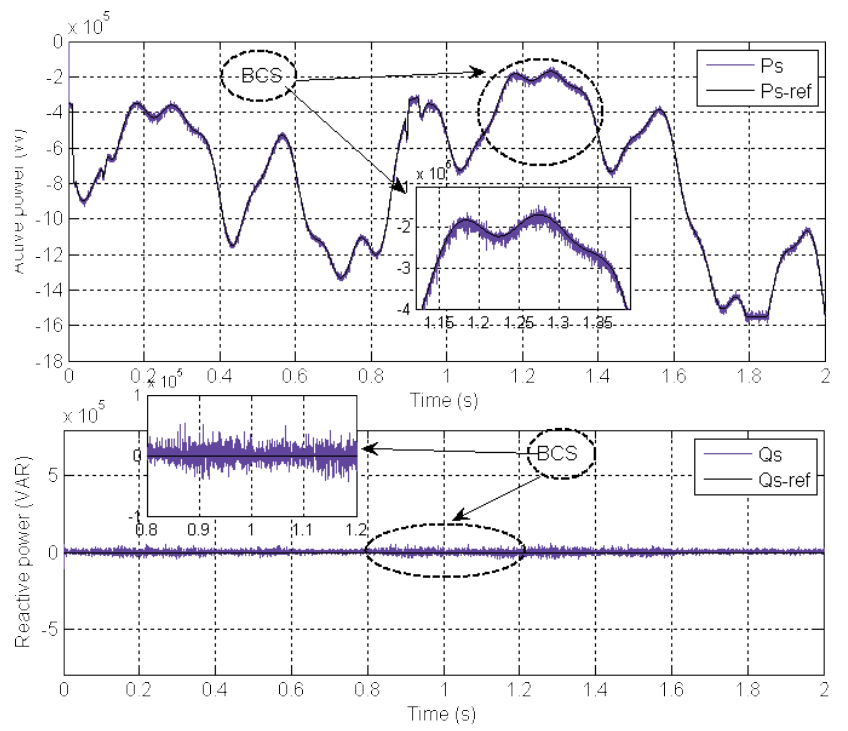

(a)
Test of parameter variation is verified to show the robustness of the two presented controls. In this test, the stator and rotor resistance values are varied to $100 \%$ of their nominal values. Simulation results of this test are presented in Figs. 15(a) and (b), and their zooms are illustrated as shown in Figs. 16(a) and (b).

Figs. 17(a) and (b) show the stator currents by using the two presented controls, conventional and optimal backstepping's control, respectively.

Moreover, Figs. 18(a) and (b) display the THD of one phase of the stator current of both controls, BCS and BCSALO, respectively.

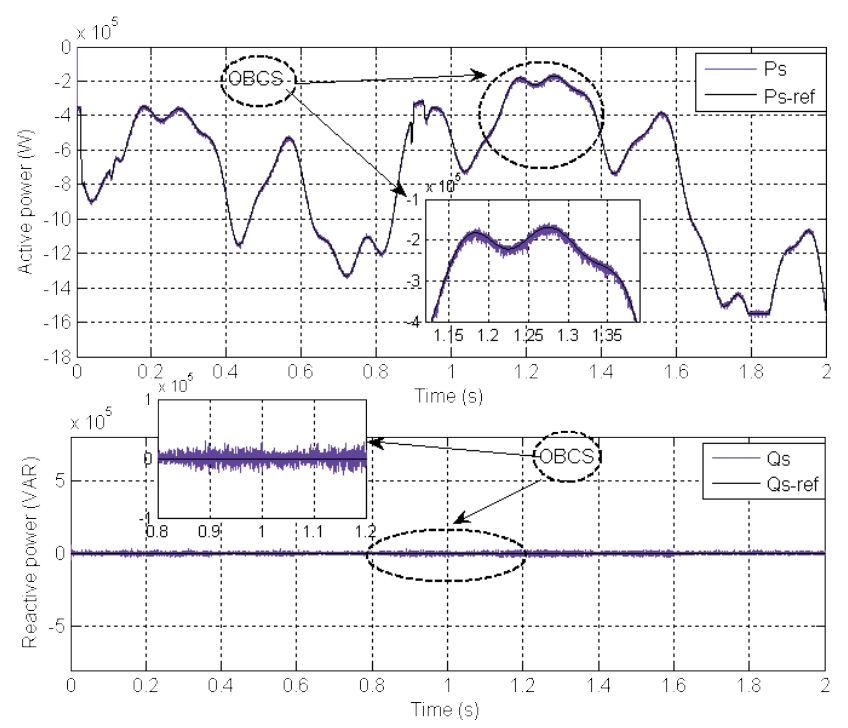

(b)

Fig. 12 Variations Stator active and reactive power response at variable wind speed by using two presented controls; (a) BCS control, (b) BCS-ALO control

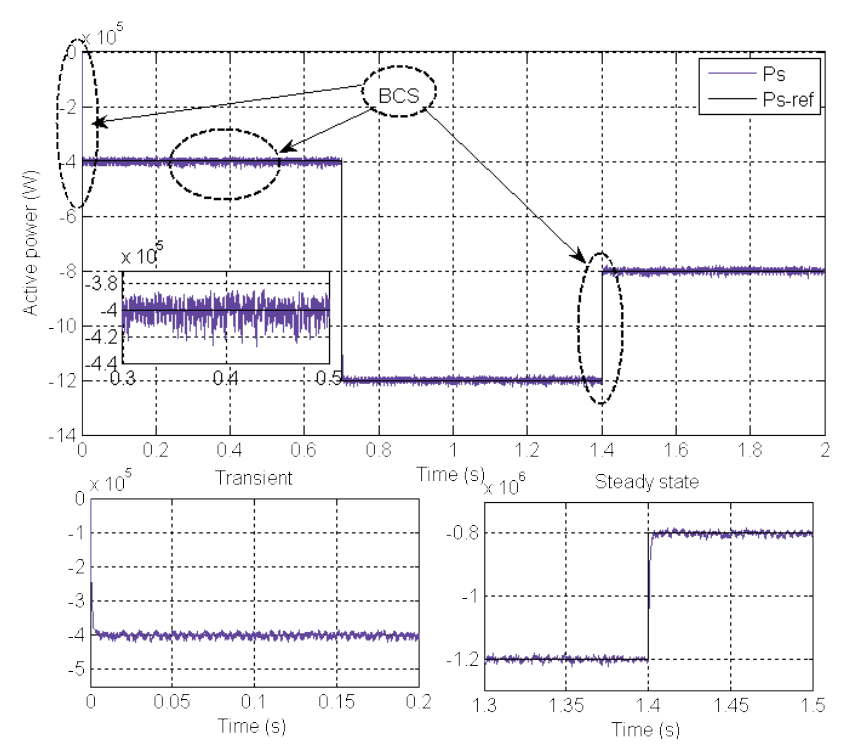

(a)

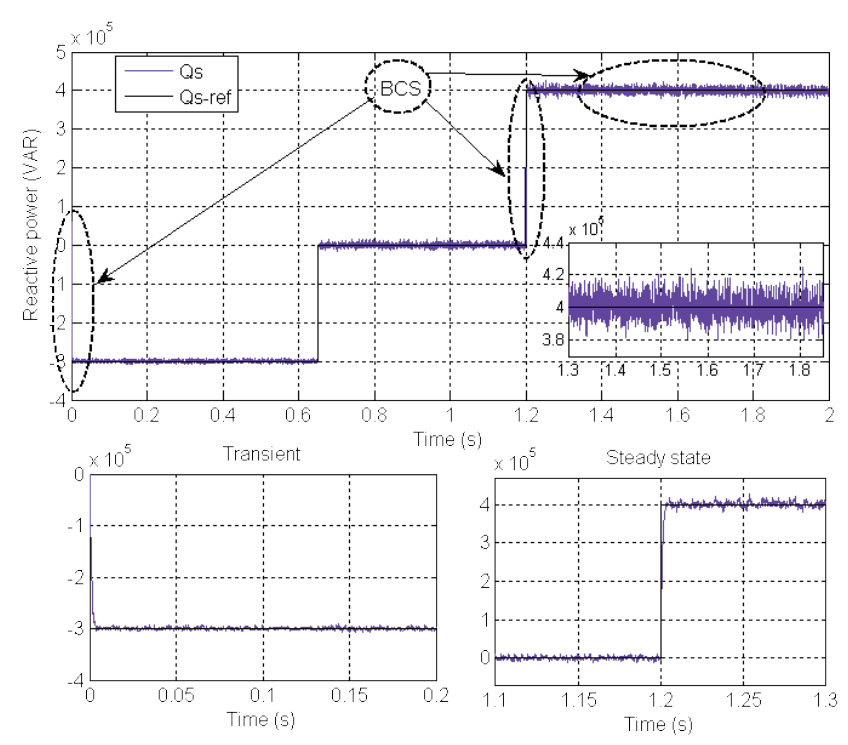

(b)

Fig. 13 Stator active and reactive power response at fixed wind speed by using BCS control; (a) Active power; (b) Reactive power 

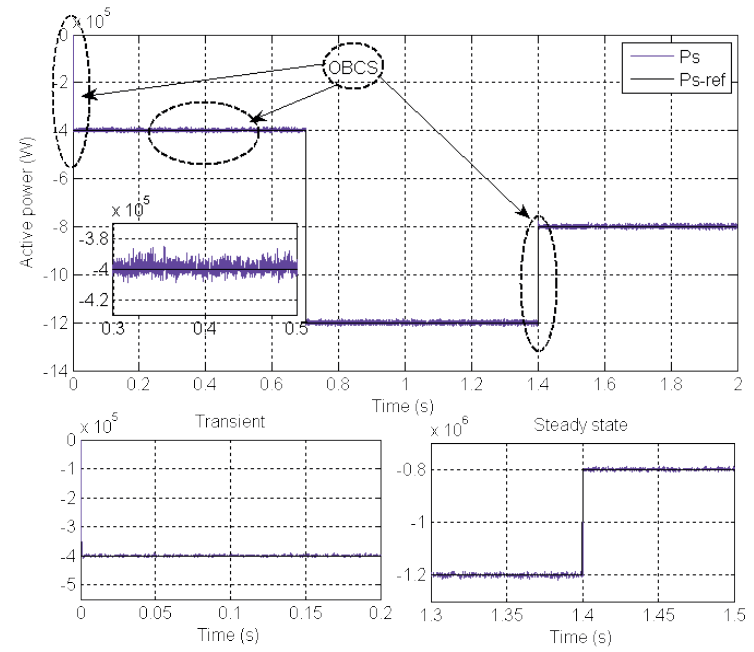

(a)
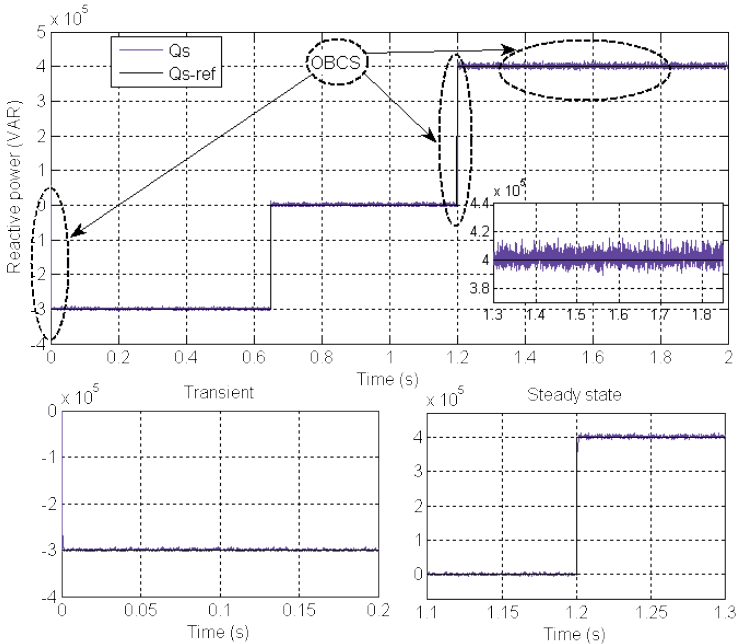

(b)

Fig. 14 Stator active and reactive power response at fixed wind speed by using BCS-ALO control; (a) Active power; (b) Reactive power

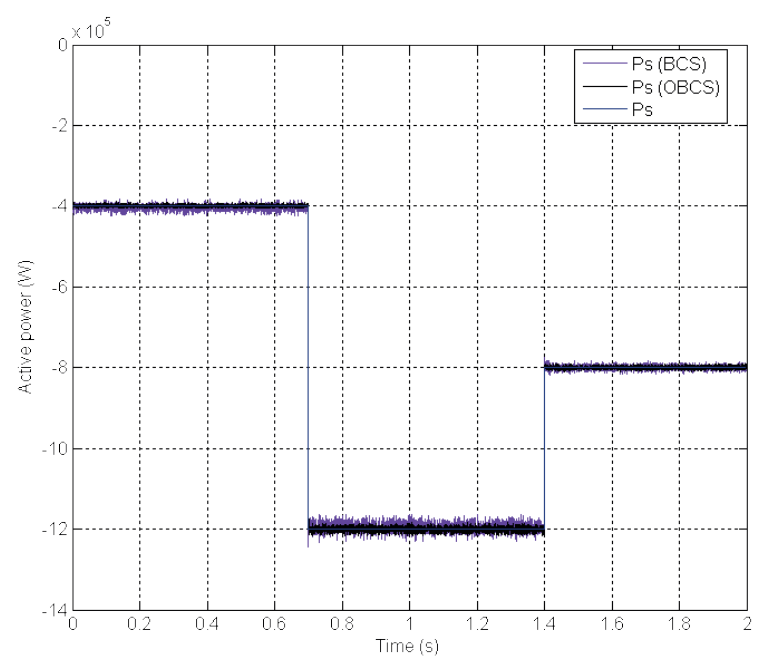

(a)

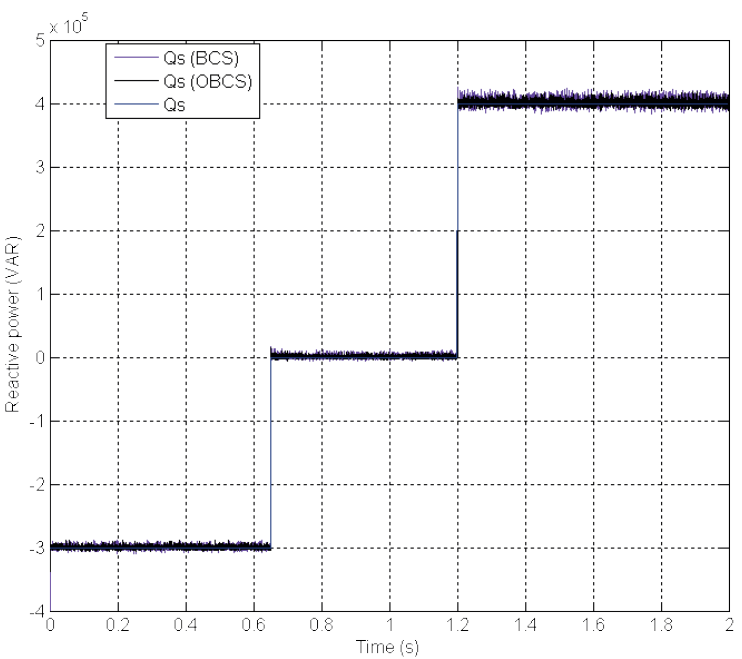

(b)

Fig. 15 Response of the active and reactive power with parameter variation by using two presented controls; (a) Active power; (b) Reactive power

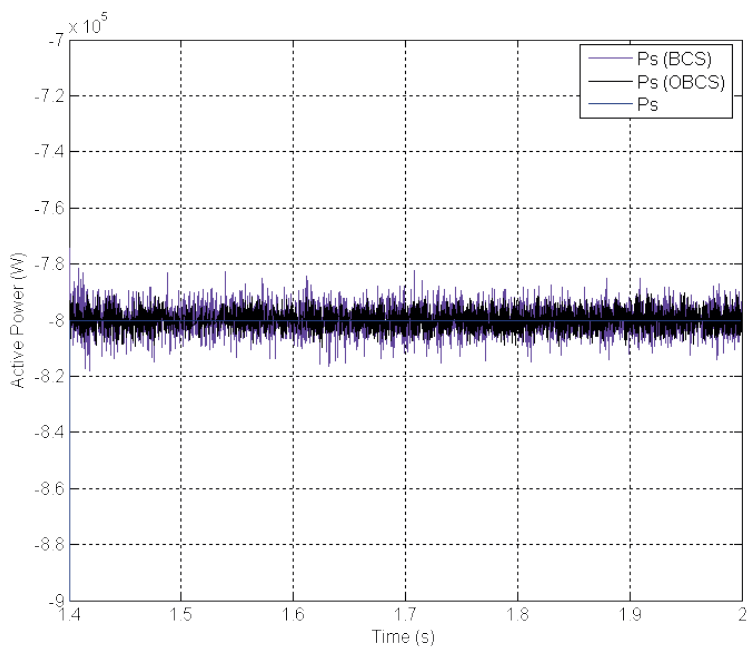

(a)

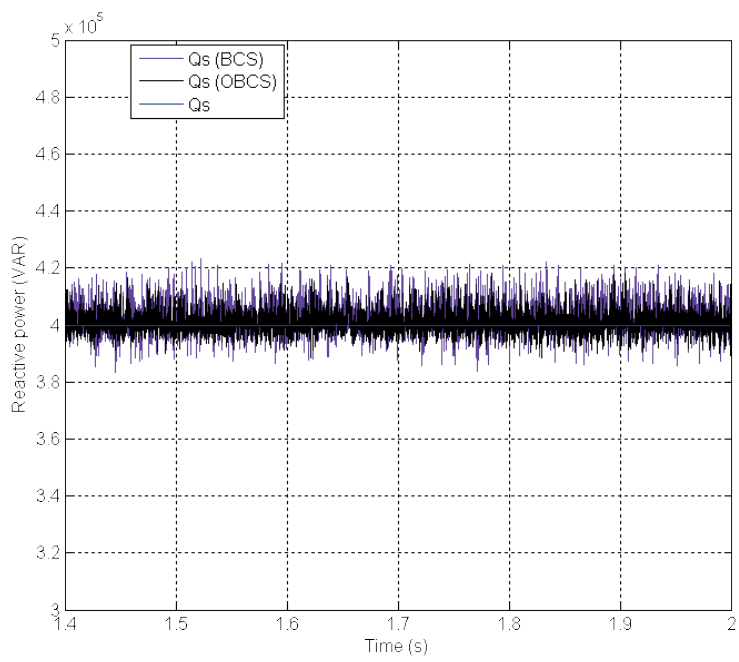

(b)

Fig. 16 Zoom in the active and reactive power with parameter variation by using two presented controls; (a) Active power; (b) Reactive power 


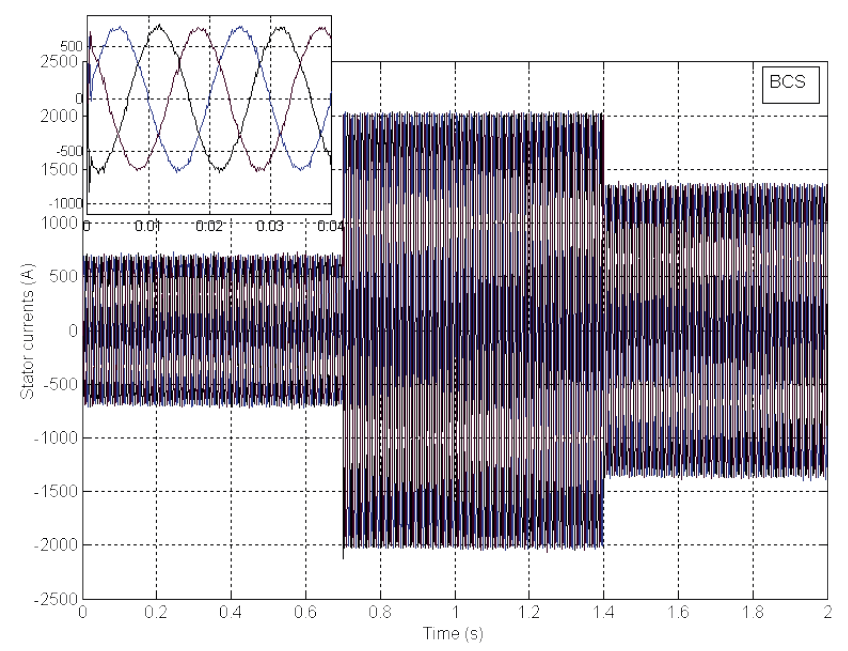

(a)

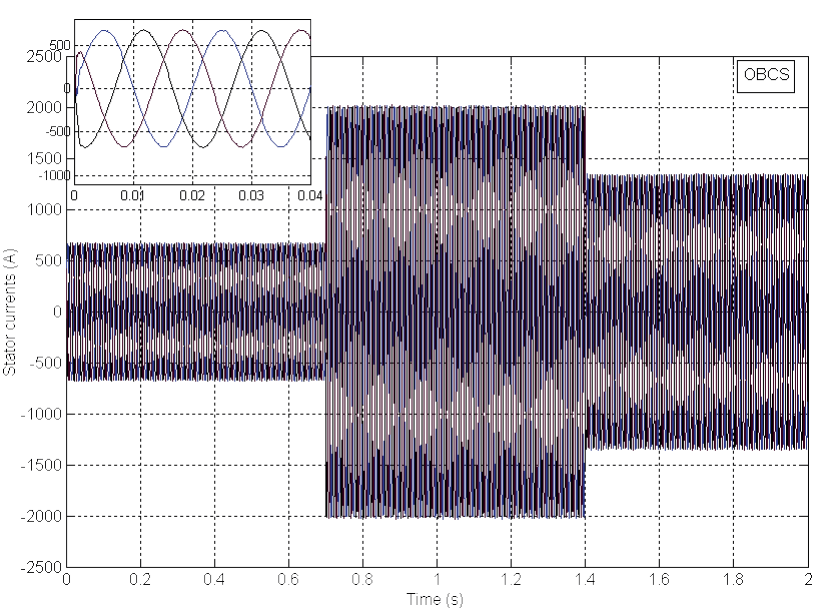

(b)

Fig. 17 Stator currents of the DFIG; (a) BCS control; (b) BCS-ALO control

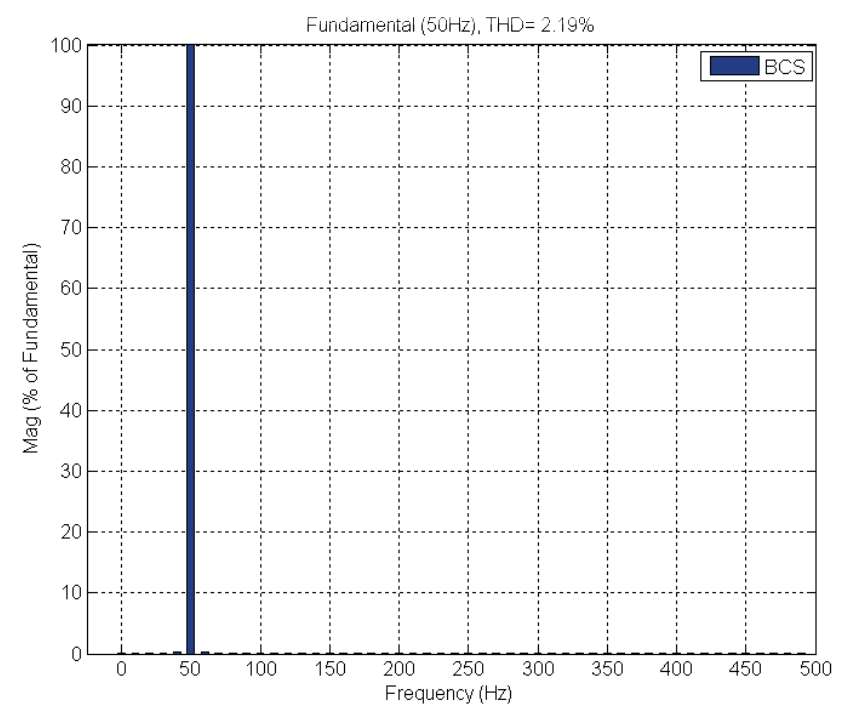

(a)

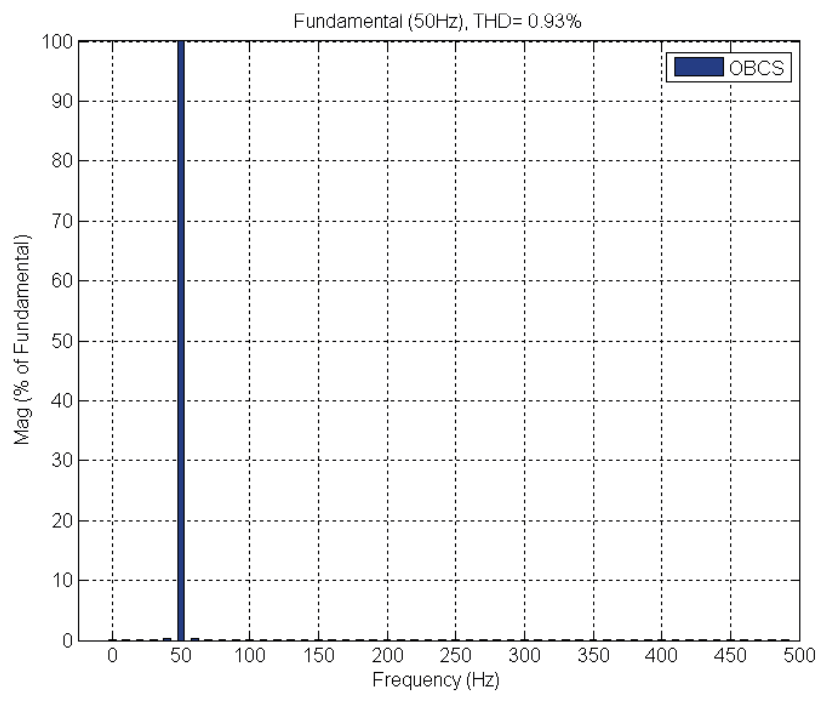

(b)

Fig. 18 Spectrum of harmonics of the stator current; (a) BCS control; (b) BCS-ALO control

As shown in Figs. 12(a) and (b), the stator active power of the DFIG follows its reference perfectly, which corresponding to the variable wind turbine power extracted by the MPPT algorithm, whereas the reactive power is held to zero to assure a unity power factor at the grid side of the DFIG.

As shown in Figs. 12(a) and (b), it is noted that the stator active and reactive powers track almost perfectly their reference values without any coupling effect between them.

Therefore, it could also be concluded that the conventional backstepping and the proposed controls have excellent efficiency in terms of reference tracking.

On the other hand, it can be seen that the ripples of the stator active and reactive power are reduced as shown in Fig. 12(b) when using the proposed BCS-ALO control compared to the conventional BCS control as shown in Fig. 12(a).
In the second test, the active and reactive power are decoupled from each other and track almost perfectly their reference values $\left(P_{s_{r} \text { ref }}\right.$ and $\left.Q_{s_{-} \text {ref }}\right)$ at fixed wind speed for the conventional BCS and the proposed BCS-ALO, as shown in Figs. 13 and 14.

However, from these figures, the proposed BCS-ALO approach shows fast and smooth response time, without overshoot, without static error and also lower ripples in active and reactive power compared to the conventional BCS strategy.

In addition, from Figs. 15(a) and (b), the analysis of the simulation results clearly showed that the variations of the DFIG parameters have an obvious influence on the stator active and reactive power curves. This influence seems more significant for the conventional BCS strategy than the optimal BCS-ALO as shown in Figs. 16(a) and (b). 
Therefore, it can be confirmed that the proposed control, OBCS based ALO, has strong robustness against parameters variation.

On the other hand, the proposed BCS-ALO control provides approximately perfect action in terms of performance and good follow-up and reducing the stator powers ripples compared to the conventional BCS control.

From Fig. 17(a) and (b), it is clear that the sinusoidal shape of the stator currents is maintained. Therefore, the stator currents, when applying the proposed BCS-ALO control are smooth as shown in Fig. 17(b) compared to the conventional BCS control as shown in Fig. 17(a).

From the results obtained in Fig. 18(b), it can be seen that the harmonics appearing in the stator currents are reduced, when using the BCS-ALO control (THD $=0.93 \%)$ compared to the conventional BCS control $(\mathrm{THD}=2.19 \%)$ as seen in Fig. 18(a).

Furthermore, the current THD of the proposed method is satisfied with less than a $\%$ limit inflicted by the IEEE 519-1992 standard [42].

Table 2 mentions the performance's quality of the BCS structure of the DFIG based on the measured ITAE, ITSE, response time, overshoot and ripples related to the active power and THD of the stator current for the two presented controls.

From Table 2, it can be concluded that the proposed BCS-ALO control is much more efficient in terms of fast response time and without static error, a reduced overshoot compared to the conventional BCS control. From these criterion values obtained in this table, it is clearly obvious that the error magnitude taken in various criteria for conventional strategy is big as compared to the proposed strategy based on ALO algorithm, which is displayed clearly by various scenarios in the simulation results.

These criteria which signify the obtained gains reduce the objective function and then permitted high performance with small errors in the control scheme when using

Table 2 The performance's quality of BCS of DFIG without and with ALO algorithm

\begin{tabular}{lcc}
\multicolumn{3}{c}{ ALO algorithm } \\
\hline \multirow{2}{*}{ Control Performances } & BCS & BCS-ALO \\
& $K_{1}=9 \mathrm{e}+003$ & $K_{1}=3.8790 \mathrm{e}+003$ \\
$K_{2}=9 \mathrm{e}+003$ & $K_{2}=4.2504 \mathrm{e}+003$ \\
\hline ITAE & $1.102 \mathrm{e}+004$ & $\mathbf{9 2 2 7}$ \\
ITSE & $2.524 \mathrm{e}+008$ & $\mathbf{2 . 1 4 6 e}+\mathbf{0 0 8}$ \\
Response time (s) & 0.0016 & $\mathbf{0 . 0 0 0 7}$ \\
Overshoot (\%) & 2.1375 & Neglected \\
Ripples (\%) & 3.0833 & $\mathbf{1 . 9 1 6 7}$ \\
THD (\%) & 2.19 & $\mathbf{0 . 9 3}$ \\
\hline
\end{tabular}

the proposed tuning method based on the ALO algorithm, compared to the conventional BCS control. These results prove the effectiveness and robustness of the proposed OBSC based ALO and its propriety for DFIG power control.

A comparative study of THD value between the proposed approach and various kinds of controls that have been proposed in the literature is presented in Table 3 [43-46].

In Table 3, DPC-PI and DPC-T2FLC are direct power control based on the PI controller and type-2 fuzzy logic controller, respectively. FOC is field-oriented control, SMC is sliding mode control, FSMC is fuzzy-sliding mode control, AFLC is artificial fuzzy logic control, ANNsC is artificial neural network control.

It can be seen from Table 3 that the proposed approach has the most reduced THD value of stator current compared to DPC-PI, DPC-T2FLC, FOC, SMC, FSMC, AFLC and $\mathrm{ANNSC}$.

Therefore, it could be concluded that the proposed OBSC control provides more excellent efficiency with low THD.

\section{Conclusion}

In this paper, the design and application of an OptimalBackstepping (OBCS) control for a wind energy conversion system (WECS) based on a doubly fed induction generator (DFIG) are established successfully to reduce the ripples of active and reactive powers, and to minimize the harmonics of the stator current.

Firstly, a mathematical model of the DFIG based WECS is presented. Then, the proposed control strategy is developed based on the Ant Lion Optimizer (ALO) algorithm, which is used to find the optimal Backstepping control parameters $\left(k_{1}\right.$ and $k_{2}$ ) of the DFIG. The Backstepping control design is based on a Lyapunov function for ensuring the stability of the overall system.

Table 3 Comparative study of THD value

\begin{tabular}{lcc}
\hline & Controller & THD (\%) \\
\hline$[43]$ & FOC-RTO & 3.21 \\
& DPC-PI & 2.59 \\
{$[44]$} & DPC-T2FLC & 1.14 \\
{$[45]$} & FOC & 3.7 \\
& SMC & 3.05 \\
{$[46]$} & FSMC & 2.85 \\
Conventional BCS & BCS & 2.19 \\
presented in this paper & & $\mathbf{0 . 9 3}$ \\
Proposed method & BCS-ALO & \\
\hline
\end{tabular}


Finally, the OBCS is employed for achieving stabilization and trajectory tracking operations of a DFIG based WECS. Simulation results demonstrate that the proposed BCS-ALO control can accomplish a faster response time and very good dynamic and static performances' tracking, in terms of reduced power ripples and lower stator current harmonics, with the smallest error between the reference and measured active and reactive power compared to the ones obtained with the conventional BCS control method.

\section{List of abbreviations}

$\begin{array}{ll}V & \text { Wind speed } \\ \Omega_{\text {mec }} & \text { Mechanical speed of DFIG } \\ \rho & \text { Air density } \\ R & \text { Blade length } \\ G & \text { Gain multiplier } \\ J & \text { Inertia of the DFIG } \\ \Omega_{t} & \text { Shaft speed } \\ f & \text { Friction coefficient } \\ g & \text { Slip of the DFIG } \\ T_{e m} & \text { Electromagnetic torque } \\ M & \text { Mutual inductance } \\ n & \text { Maximum number of ants } \\ r(t) & \text { Random function } \\ t & \text { Step of random walk } \\ A n t_{i, j} & \text { Value of the j-th variable of i-th ant } \\ M_{o a} & \text { Matrix for maintaining the fitness of any ant } \\ M_{\text {ant lion }} & \text { Matrix for saving the location of any ant lion }\end{array}$

\section{References}

[1] Mohammadi, J., Vaez-Zadeh, S., Afsharnia, S.,Daryabeigi, E. "A Combined Vector and Direct Power Control for DFIG-Based Wind Turbines", IEEE Transactions on Sustainable Energy, 5(3), pp. 767$775,2014$.

https://doi.org/10.1109/TSTE.2014.2301675

[2] Ishaq, H., Dincer, I. "A comparative evaluation of OTEC, solar and wind energy-based systems for clean hydrogen production", Journal of Cleaner Production, 246, Article number: 118736, 2020. https://doi.org/10.1016/j.jclepro.2019.118736

[3] Ahlem, C., Benretem, A., Dobrev, I., Barkati, B. "Comparative study of two control strategies proportional integral and fuzzy logic for the control of a doubly fed induction generator dedicated to a wind application", International Journal of Power Electronics and Drive Systems, 11(1), pp. 263-274, 2020. https://doi.org/10.11591/ijpeds.v11.i1.pp263-274

[4] Kassem, A. M., Hasaneen, K. M., Yousef, A. M. "Dynamic modelling and robust power control of DFIG driven by wind turbines at infinite grid", International Journal of Electrical Power \& Energy Systems, 44(1), pp. 375-382, 2013.

https://doi.org/10.1016/j.ijepes.2011.06.038
It would really like to implement this approach on a real system, in the near future research.

\section{Acknowledgement}

The project presented in this article is supported by Directorate General for Scientific Research and Technological Development (DGRSDT), Ministry of Higher Education and Scientific Research - Algeria.

\begin{tabular}{|c|c|}
\hline Ant lion $_{i, j}$ & Value of the $\mathrm{j}$-th variable of $\mathrm{i}$-th ant lion \\
\hline$M_{\text {oal }}$ & Matrix for keeping the fitness of any ant lion \\
\hline$A_{i}$ & Minimum of random walk of $\mathrm{i}$-th variable \\
\hline$d$ & Number of variables \\
\hline$C_{i}^{t}$ & Minimum of $\mathrm{i}$-th variable at $\mathrm{t}$-th iteration \\
\hline$C^{t}$ & Minimum of all variables at $\mathrm{t}$-th iteration \\
\hline$M_{\text {ant }}$ & Minimum of all variables for i-th ant \\
\hline$C_{j}^{t}$ & Matrix for saving the location of any ant \\
\hline$D_{i}^{t}$ & Maximum of $\mathrm{i}$-th variable at $\mathrm{t}$-th iteration \\
\hline$D^{t}$ & $\begin{array}{l}\text { Vector including the maximum of all } \\
\text { variables at } t \text {-th iteration }\end{array}$ \\
\hline$A n t_{i}^{t}$ & The position of $\mathrm{i}$-th ant at $\mathrm{t}$-th iteration \\
\hline$D_{j}^{t}$ & Maximum of all variables for $\mathrm{i}$-th ant \\
\hline$I$ & Ratio equals to $10^{w t} / T$ \\
\hline Ant lion $_{i}^{t}$ & $\begin{array}{l}\text { Location of the chosen } \mathrm{j} \text {-th ant lion at } \mathrm{t} \text {-th } \\
\text { iteration }\end{array}$ \\
\hline Dim & Dimension \\
\hline
\end{tabular}

[5] Lagudu, V. S. K., Ananth, D. V. N., Madichetty, S. "Independent control of active and reactive power for grid connected DFIG using reference power based improved field-oriented control scheme", International Journal of Ambient Energy, 2020 https://doi.org/10.1080/01430750.2020.1818123

[6] Zeghdi, Z., Barazane, L., Larabi, A. "Field Oriented Control of Doubly Fed Induction Generator Integrated in Wind Energy Conversion System Using Artificial Neural Networks", In: 2018 International Conference on Electrical Sciences and Technologies in Maghreb (CISTEM), Algiers, Algeria, 2018, pp. 1-7. https://doi.org/10.1109/CISTEM.2018.8613558

[7] Bekakra, Y. Attous, D. B. "Optimal tuning of PI controller using PSO optimization for indirect power control for DFIG based wind turbine with MPPT", International Journal of System Assurance Engineering and Management, 5(3), pp. 219-229, 2014. https://doi.org/10.1007/s13198-013-0150-0

[8] Jia, L., Zhao, X. "An Improved Particle Swarm Optimization (PSO) Optimized Integral Separation PID and its Application on Central Position Control System", IEEE Sensors Journal, 19(16), pp. 7064 $7071,2019$.

https://doi.org/10.1109/JSEN.2019.2912849 
[9] Marouane, R., Malika, Z. "Particle swarm optimization for tuning PI controller in FOC chain of induction motors", In: 2018 4th International Conference on Optimization and Applications (ICOA), Mohammedia, Morocco, 2018, pp. 1-5. https://doi.org/10.1109/ICOA.2018.8370512

[10] Bahgaat, N. K., Hassan, M. M. "Swarm Intelligence PID Controller Tuning for AVR System", In: Azar, A. T., Vaidyanathan, S. (eds.) Advances in Chaos Theory and Intelligent Control, Springer, Cham, Switzerland, 2016, pp. 791-804. https://doi.org/10.1007/978-3-319-30340-6_33

[11] Zeghdi, Z., Barazane, L., Larabi, A., Samir, A., Khechiba, K. "Artificial Neural Networks (ANNs)-Based Robust Tracking Control for DFIG integrated in WECS", In: 2018 International Conference on Applied Smart Systems (ICASS), Medea, Algeria, 2018, pp. 1-6. https://doi.org/10.1109/ICASS.2018.8652023

[12] Azeem, B., Ullah, Z., Rehman, F., Mehmood, C. A., Ali, S. M., Khan, B., Hussain, I., Zeb, K., Azeem, S., Haider, A. "Robust neural network scheme for generator side converter of doubly fed induction generator", In: 2017 International Symposium on Recent Advances in Electrical Engineering (RAEE), Islamabad, Pakistan, 2017, pp. 1-6.

https://doi.org/10.1109/RAEE.2017.8246149

[13] Louarem, S. L. S., Belkhiat, D. E. C., Bouktir, T., Belkhiat, S. "An Efficient Active and Reactive Power Control of DFIG for a Wind Power Generator", Engineering, Technology \& Applied Science Research, 9(5), pp. 4775-4782, 2019.

https://doi.org/10.48084/etasr.3007

[14] Cherifi, D., Miloud, Y. "Hybrid Control Using Adaptive Fuzzy Sliding Mode Control of Doubly Fed Induction Generator for Wind Energy Conversion System", Periodica Polytechnica Electrical Engineering and Computer Science, 64(4), pp. 374-381, 2020. https://doi.org/10.3311/PPee.15508

[15] Lin, Y.-C., Balas, V. E., Yang, J-F., Chang, Y.-H. "Adaptive TakagiSugeno Fuzzy Model Predictive Control for Permanent Magnet Synchronous Generator-Based Hydrokinetic Turbine Systems", Energies, 13(20), Article number: 5296, 2020. https://doi.org/10.3390/en13205296

[16] Venkataramana Naik, N., Singh, S. P., Panda, A. K. "An Interval Type-2 Fuzzy-Based DTC of IMD Using Hybrid Duty Ratio Control", IEEE Transactions on Power Electronics, 35(8), pp. 84438451,2020 .

https://doi.org/10.1109/TPEL.2020.2965722

[17] Ponce, P., Ponce, H., Molina, A. "Doubly fed induction generator (DFIG) wind turbine controlled by artificial organic networks", Soft Computing, 22(9), pp. 2867-2879, 2018. https://doi.org/10.1007/s00500-017-2537-3

[18] Ouada, L., Benaggoune, S., Belkacem, S. "Neuro-fuzzy Sliding Mode Controller Based on a Brushless Doubly Fed Induction Generator", International Journal of Engineering, 33(2), pp. 248256, 2020.

https://doi.org/10.5829/ije.2020.33.02b.09

[19] Kumar, V., Pandey, A. S., Sinha, S. K. "Stability Improvement of DFIG-Based Wind Farm Integrated Power System Using ANFIS Controlled STATCOM", Energies, 13(18), Article No. 4707, 2020. https://doi.org/10.3390/en13184707
[20] Benbouhenni, H., Boudjema, Z., Belaidi, A. "DPC Based on ANFIS Super-Twisting Sliding Mode Algorithm of a Doubly Fed Induction Generator for Wind Energy System", Journal Européen des Systèmes Automatisés, 53(1), pp. 69-80, 2020. https://doi.org/10.18280/jesa.530109

[21] Drhorhi, I., Fadili, A. E., Berrahal, C., Lajouad, R., El Magri, A., Giri, F., Azar, A. T., Vaidyanathan, S. "Adaptive backstepping controller for DFIG-based wind energy conversion system", In: Vaidayanathan, S., Azar, A. T. (eds.) Backstepping Control of Nonlinear Dynamical Systems, Academic Press, Cambridge, USA, 2021. pp. 235-260. https://doi.org/10.1016/B978-0-12-817582-8.00018-0

[22] Djeriri, Y. "Lyapunov-Based Robust Power Controllers for a Doubly Fed Induction Generator", Iranian Journal of Electrical and Electronic Engineering, 16(4), pp. 551-558, 2020. https://doi.org/10.22068/IJEEE.16.4.551

[23] El Mourabi, Y., Derouich, A., El Ghzizal, A., Bouchnaif, J., El Ouanjli, N., Zamzoum, O., Mezioui. K., BOSSOUfI, B. "Implementation and validation of backstepping control for PMSG wind turbine using dSPACE controller board", Energy Reports, 5, pp. 807-821, 2019. https://doi.org/10.1016/j.egyr.2019.06.015

[24] Adekanle, O. S., Guisser, M., Abdelmounim, E., Aboulfatah, M. "Observer-Based Adaptive Backstepping Control of GridConnected Wind Turbine Under Deep Grid Voltage Dip", In: El Hani, S., Essaaidi, M. (eds.) Recent Advances in Electrical and Information Technologies for Sustainable Development, Springer, Cham, Switzerland, 2019, pp. 75-84.

https://doi.org/10.1007/978-3-030-05276-8_9

[25] Nadour, M., Essadki, A., Fdaili M., Nasser, T. "Advanced Backstepping Control of a Wind Energy Conversion System Using a Doubly-Fed Induction Generator", In: 2017 International Renewable and Sustainable Energy Conference (IRSEC), Tangier, Morocco, 2017, pp. 1-6. https://doi.org/10.1109/IRSEC.2017.8477276

[26] Ullah, N., Aziz Al Ahmadi, A. "Variable Structure Back-Stepping Control of Two-stage Three Phase Grid Connected PV Inverter", Periodica Polytechnica Electrical Engineering and Computer Science, 64(3), pp. 239-246, 2020. https://doi.org/10.3311/PPee.15412

[27] El Maguiri, O., Moussaif, D., Smma, E. a., Abdelmajid, F., Akhiate, A. "Backstepping nonlinear control to maximize energy capture in a variable speed wind turbine", International Journal of Electrical and Computer Engineering, 9(6), pp. 4758-4766, 2019.

https://doi.org/10.11591/ijece.v9i6.pp4758-4766

[28] Bechouat, M., Sedraoui, M., Soufi, Y., Yousfi, L. Borni, A., Kahla, S. "Particle Swarm Optimization Backstepping Controller for a Grid-Connected PV/Wind Hybrid System", Journal of Engineering Science and Technology Review, 10(1), pp. 91-99, 2017. https://doi.org/10.25103/jestr.101.13

[29] Hassan, S., Abdelmajida, B., Mourad, Z., Aicha, S., Abdenaceur, B. "PSO-backstepping controller of a grid connected DFIG based wind turbine", International Journal of Electricaland Computer Engineering, 10(1), pp. 856-867, 2020.

https://doi.org/10.11591/ijece.v10i1.pp856-867 
[30] Moutchou, M., Mahmoudi, H., Abbou, A. "A new technique of backstepping control parameters determination using genetic algorithm", In: 2014 International Renewable and Sustainable Energy Conference (IRSEC), Ouarzazate, Morocco, 2014, pp. 475-480. https://doi.org/10.1109/IRSEC.2014.7059744

[31] Holland, J. H. "Genetic algorithms", Scientific American, 267(1), pp. 66-72, 1992. https://doi.org/10.1038/scientificamerican0792-66

[32] Srinivas, J., Giri, R., Yang, S-H. "Optimization of multi-pass turning using particle swarm intelligence", The International Journal of Advanced Manufacturing Technology 40(1), pp. 56-66, 2009. https://doi.org/10.1007/s00170-007-1320-5

[33] Pothiya, S., Ngamroo, I., Kongprawechnon, W. "Ant colony optimisation for economic dispatch problem with non-smooth cost functions", International Journal of Electrical Power \& Energy Systems, 32(5), pp. 478-487, 2010.

https://doi.org/10.1016/j.ijepes.2009.09.016

[34] Yang, X-S. "Firefly algorithm, stochastic test functions and design optimisation", International Journal of Bio-Inspired Computation, 2(2), pp. 78-84, 2010. https://doi.org/10.1504/IJBIC.2010.032124

[35] Mirjalili, S., Mirjalili, S. M., Lewis, A. "Grey Wolf Optimizer", Advances in Engineering Software, 69, pp. 46-61, 2014. https://doi.org/10.1016/j.advengsoft.2013.12.007

[36] Kaveh, A. Mahdavi, V. "Colliding Bodies Optimization method for optimum design of truss structures with continuous variables", Advances in Engineering Software, 70, pp. 1-12, 2014. https://doi.org/10.1016/j.advengsoft.2014.01.002

[37] Bekakra, Y., Labbi, Y., Attous, D. B., Malik, O. P. "Rooted Tree Optimization Algorithm to Improve DTC Response of DFIM", Journal of Electrical Engineering Technology, 16(5), pp. 24632483, 2021.

https://doi.org/10.1007/s42835-021-00796-4

[38] Bekakra, Y., Zellouma, L., Malik, O. "Improved predictive direct power control of shunt active power filter using GWO and ALO - Simulation and experimental study", Ain Shams Engineering Journal, 2021.

https://doi.org/10.1016/j.asej.2021.04.028

\section{Appendix}

Table 4 Wind Turbine parameters

\begin{tabular}{lc}
\hline Gearbox ratio, $G$ & 90 \\
Number of blades & 3 \\
Blade radius, $R$ & $35.25 \mathrm{~m}$ \\
Nominal wind speed, $v$ & $16 \mathrm{~m} / \mathrm{s}$ \\
Moment of inertia, $J$ & $1000 \mathrm{Kg} \cdot \mathrm{m}^{2}$ \\
Viscous friction coefficient, $f r$ & $0.0024 \mathrm{~N} \cdot \mathrm{m} \cdot \mathrm{s}^{-1}$ \\
\hline
\end{tabular}

[39] Mirjalili, S. "The Ant Lion Optimizer", Advances in Engineering Software, 83, pp. 80-98, 2015. https://doi.org/10.1016/j.advengsoft.2015.01.010

[40] Ali, E. S., Abd Elazim, S. M., Abdelaziz, A. Y. "Ant Lion Optimization Algorithm for optimal location and sizing of renewable distributed generations", Renewable Energy, 101, pp. 13111324, 2017.

https://doi.org/10.1016/j.renene.2016.09.023

[41] Dinakara Prasasd Reddy P., Veera Reddy V.C., Gowri Manohar T. "Ant Lion optimization algorithm for optimal sizing of renewable energy resources for loss reduction in distribution systems", Journal of Electrical Systems and Information Technology, 5(3), pp. 663$680,2018$.

https://doi.org/10.1016/j.jesit.2017.06.001

[42] American National Standard "IEEE Std 519-1992 IEEE Recommended Practices and Requirements for Harmonic Control in Electrical Power Systems", Institute of Electrical and Electronics Engineers Inc., New York, NY, USA, 1993. https://doi.org/10.1109/IEEESTD.1993.114370

[43] Benamor, A., Benchouia, M. T., Srairi, K., Benbouzid, M. E. H. "A new rooted tree optimization algorithm for indirect power control of wind turbine based on a doubly-fed induction generator", ISA Transactions, 88, pp. 296-306, 2019. https://doi.org/10.1016/j.isatra.2018.11.023

[44] Benbouhenni, H., , Belaidi, A, Boudjema, Z. "Power ripple reduction of DPC DFIG drive using ANN controller", Acta Electrotechnica et Informatica, 20(1), pp. 15-22, 2020. https://doi.org/10.15546/aeei-2020-0003

[45] Amrane, F., Chaiba, A., Babes, B. E., Mekhilef, S. "Design and implementation of high performance field oriented control for grid-connected doubly fed induction generator via hysteresis rotor current controller", Revue Roumaine Sciences TechniquesElectrotechnique Et Énergétique, 61(4), pp. 319-324, 2016.

[46] Benbouhenni, H., Boudjema, Z., Belaidi, A. "Power Control of DFIG in WECS Using DPC and NDPC-NPWM Methods", Mathematical Modelling of Engineering Problems, 7(2), pp. 223-236, 2020. https://doi.org/10.18280/mmep.070208

Table 5 Doubly Fed Induction Generator parameters

\begin{tabular}{lc}
\hline Number of pairs of poles, $p$ & 2 \\
Rated power, $P_{n}$ & $1.5 \mathrm{MW}$ \\
Stator rated frequency, $f$ & $50 \mathrm{~Hz}$ \\
Stator rated voltage, $V_{s}$ & $398 / 690 \mathrm{~V}$ \\
Rated current, $I_{n}$ & $1900 \mathrm{~A}$ \\
Stator inductance, $L_{s}$ & $0.0137 \mathrm{H}$ \\
Rotor inductance, $L_{r}$ & $0.0136 \mathrm{H}$ \\
Mutual inductance, $L_{m}$ & $0.0135 \mathrm{H}$ \\
Stator inductance, $R_{s}$ & $0.012 \Omega$ \\
Rotor inductance, $R_{r}$ & $0.021 \Omega$ \\
\hline
\end{tabular}

